\title{
Unwanted pregnancy and induced abortion: Data from men and women in Rajasthan, India
}

\author{
Batya Elul \\ Population Council \\ Sandhya Barge \\ Shalini Verma \\ Population Council \\ Nayan Kumar \\ Hillary J. Bracken \\ Population Council
}

See next page for additional authors

Follow this and additional works at: https://knowledgecommons.popcouncil.org/departments_sbsr-rh

Part of the Family, Life Course, and Society Commons, International Public Health Commons, and the Maternal and Child Health Commons

How does access to this work benefit you? Let us know!

\section{Recommended Citation}

Elul, Batya, Sandhya Barge, Shalini Verma, Nayan Kumar, Hillary J. Bracken, and Hemlata Sadhwani. 2004. "Unwanted pregnancy and induced abortion: Data from men and women in Rajasthan, India." New Delhi: Population Council. 


\section{Authors}

Batya Elul, Sandhya Barge, Shalini Verma, Nayan Kumar, Hillary J. Bracken, and Hemlata Sadhwani 


\title{
Unwanted Pregnancy and Induced Abortion: Data from Men and Women in Rajasthan, India
}

\author{
Batya Elul \\ Sandhya Barge \\ Shalini Verma \\ Nayan Kumar \\ Hillary Bracken \\ Hemlata Sadhvani
}


This report is the result of a collaborative project between the Population Council and the Centre for Operations Research and Training, conducted as part of a Council programme of research on unwanted pregnancy and induced abortion in Rajasthan, India. Designed as a complement to service-delivery activities being undertaken in Rajasthan by the Indian non-governmental reproductive health service provider Parivar Seva Sanstha, the programme of research aimed to provide a multi-faceted picture of the on-the-ground realities related to unwanted pregnancy and abortion in six districts of Rajasthan.

\section{For additional copies of this report, please contact:}

Ms. Vijaya Nidadavolu

Population Council

Zone 5A, Ground Floor

India Habitat Centre

Lodi Road

New Delhi 110 003, INDIA

Tel: 91-11-2464 2901/2

Fax: 91-11-2464 2903

Email: vijaya@pcindia.org

\section{Ms. Virginia Kallianes}

Population Council

1 Dag Hammarskjold Plaza

New York, NY 10017 USA

Tel: 1-212-339-0500

Fax: 1-212-755-6052

Email:vkallianes@popcouncil.org

\section{Dr. Sandhya Barge}

Centre for Operations Research and Training 402 Woodland Apartment, Race Course Circle Vadodara 390 007, INDIA

Tel: 91-265-234 1253

Fax: 91-265-234 2941

Email: cort10@satyam.net.in

\section{For more information on Parivar Seva Sanstha's activities in Rajasthan, please contact:}

\section{Ms. Poonam Arora}

Parivar Seva Sanstha

C-374 Defence Colony

New Delhi 110 024, INDIA

Tel: $91-11-24337142 / 2524 / 7712$

Fax: 91-11-2433 6337/2585/6710

Email:parivarseva@vsnl.com
Parivar Seva Sanstha

Project Office (Rajasthan)

Flat No. A 1/1, Yamuna Path

Ganga Path, Suraj Nagar

West Civil Lines

Jaipur 302 001, INDIA

Tel: 91-141-222 1274

Fax: 91-141-222 1196

Email: parivarsevaro-jp@eth.net

The Population Council is an international, non-profit, non-governmental organisation that seeks to improve the well-being and reproductive health of current and future generations around the world and to help achieve a humane, equitable and sustainable balance between people and resources. The Council conducts biomedical, social science and public health research and helps build research capacities in developing countries.

The Centre for Operations Research and Training (CORT) is a leading multidisciplinary social science research and training organisation with headquarters in Vadodara, Gujarat. Over the last 13 years it has undertaken diagnostic, evaluation and operations research on various components of reproductive health, population, women and other social issues.

Parivar Seva Sanstha is a national non-governmental organisation providing reproductive health services with an emphasis on family planning. Registered in 1978, the organisation today has a strong network of 40 reproductive health clinics, a contraceptive products marketing and distribution system, and numerous projects and outreach activities located in 21 states of India. 


\section{Contents}

Acknowledgements $\quad$ iv

Acronyms $\quad v$

Abstract $\quad$ vi

Chapter 1: Introduction $\quad 1$

Background

1

Study objectives $\quad 2$

Sampling 3

Data collection and analysis $\quad 4$

Sample coverage $\quad 6$

$\begin{array}{ll}\text { About this report } & 7\end{array}$

Chapter 2: Characteristics of Households and Respondents $\quad 8$

$\begin{array}{ll}\text { Characteristics of households } & 8\end{array}$

Characteristics of female respondents $\quad 9$

$\begin{array}{ll}\text { Characteristics of male respondents } & 9\end{array}$

Chapter 3: Prevalence of Unwanted Pregnancy and Induced Abortion $\quad 14$

$\begin{array}{ll}\text { Unwanted pregnancy levels } & 14\end{array}$

$\begin{array}{ll}\text { Induced abortion levels } & 14\end{array}$

$\begin{array}{ll}\text { Chapter 4: Abortion Experiences } & 19\end{array}$

Reasons for abortion and abortion decision-making $\quad 19$

$\begin{array}{ll}\text { Gestational age } & 20\end{array}$

Treatments and providers $\quad 20$

Post-abortion experiences $\quad 26$

Chapter 5: Knowledge of and Attitudes Towards Abortion $\quad 29$

Abortion legality $\quad 29$

$\begin{array}{ll}\text { Abortion risks and services } & 31\end{array}$

Sex determination and sex-selective abortion 34

Chapter 6: Summary of Findings and Conclusion $\quad 36$

$\begin{array}{ll}\text { References } & 40\end{array}$

$\begin{array}{lll}\text { Authors } & 42\end{array}$ 


\section{Acknowledgements}

This study and report could not have been completed without the hard work, commitment and contributions of many people. We thank the 31 interviewers who collected data in both near and far sites in Rajasthan for their persistence in what proved to an extremely challenging undertaking. We are similarly indebted to the men and women who opened their doors to us and shared their experiences and opinions, even on such a sensitive topic as abortion.

We also thank many colleagues for their assistance at different stages of the study. Mrs. Sudha Tewari, Ms. Sumita Taneja and Mr. B.N.N. Chowdhary from Parivar Seva Sanstha in New Delhi, India provided helpful comments early on when we were conceptualising the study, as did Dr. Liliana Risi of Marie Stopes International in London, UK and Dr. Bela Ganatra of Ipas in Pune, India. Members of the technical advisory group for the Population Council's programme of research on unwanted pregnancy and induced abortion—Dr. Dinesh Agarwal, Dr. Sharad Iyengar, Dr. Bert Pelto, Dr. Rajani Ved, Dr. Ravi Verma and Dr. Leela Visaria—similarly provided valuable guidance. Dr. Arvind Pandey of the Institute for Research in Medical Statistics in New Delhi, India offered important inputs with the sampling design. Ms. Seema Narverkar of the Centre for Operations Research and Training in Vadodara, India contributed valuable assistance with data cleaning and analysis. We also thank Ms. Vijaya Nidadavolu for assisting in the preparation of this report. Finally, we are grateful to an anonymous donor for supporting this study. 


\title{
Acronyms
}

\author{
CORT Centre for Operations Research and Training \\ ICMR Indian Council of Medical Research \\ MTP Medical Termination of Pregnancy \\ NFHS National Family Health Survey
}




\section{Abstract}

As part of a Population Programme of Research on unwanted pregnancy and induced abortion in Rajasthan, the Population Council and the Centre for Operations Research and Training conducted a community-based study of unwanted pregnancy and induced abortion in six districts of Rajasthan. Multistage stratified sampling techniques were used to identify 3,266 ever-married women aged 15-44 and 602 of their husbands in purposively selected district headquarters and several medium-sized towns, as well as in villages and smaller towns surrounding those urban localities. Detailed pregnancy histories yielded data on levels of unwanted pregnancy and induced abortion in the sampled areas in Rajasthan. Women with abortions in the five years preceding the survey provided information about their experiences, including why, where and how they obtained services. Men and women were also asked about their knowledge of and opinions about abortion law, risks, and services.

The study shows that rates of abortion are considerable with 13 percent of women reporting at least one induced abortion. The vast majority of women had abortions because they ( 59 percent) or their spouse (18 percent) wanted to limit their family size or space their childbearing (22 percent). Sex preferences appear to drive only a very small proportion of women ( 3 percent) to terminate their pregnancies. Women's husbands often participated in the decision to seek an abortion ( 55 percent) or were solely responsible for the decision ( 25 percent).

For many women, abortion is often a process that entails the consumption of home remedies, as well as the use of services in the informal and formal sectors. Twenty percent of women with abortions reportedly used a home remedy or obtained services from an informal provider in an attempt to terminate their pregnancies. As these actions were not always successful, the majority ( 89 percent) of women eventually sought services from the formal sector. Even when seeking services in the formal sector, though, some women had to visit more than one provider to terminate their pregnancies. Private-sector doctors emerged as important providers of abortion in both urban and rural areas, used by 43 percent of all women seeking services in the formal sector.

Access to services and quality treatment was particularly poor in rural areas. Only five percent of rural women with abortions obtained the service locally, in their own village. One-quarter (24 percent) travelled over one hour to reach an abortion provider. Although provisions for free abortion services exist in the public sector, both rural and urban women incurred at least some out-of-pocket costs when obtaining an abortion. In many cases (34 percent), these costs were well over 500 Indian Rupees.

Post-abortion contraception counselling and adoption was low, representing a significant lost opportunity. While most women obtaining abortions desired to limit or space their childbearing, the majority ( 60 percent) of them did not receive any information or counselling regarding family planning, particularly in rural areas where only 17 percent indicated that providers discussed family planning with them. Similarly, while 60 percent of 
women adopted a method of family planning after their abortions, use was sometimes short-lived, limited to less than one month in 17 percent of cases.

Levels of post-abortion morbidity were relatively modest in our study and surprisingly similar across our urban and rural samples. Nearly all women who experienced morbidity, however, indicated that the problems they encountered affected their daily life-leaving them bedridden for atleast one day ( 83 percent) or unable to complete routine household chores ( 83 percent). Nearly half ( 45 percent) of women with post-abortion complications sought formal treatment for them and a fair number (13 percent) were hospitalised.

Knowledge of the legality of abortion was low with only 16 percent of men and 17 percent of women aware of the legal right to pregnancy termination. Rural women were particularly unlikely to know that abortion is legal. When combined with poor access to services in rural areas, this lack of information may contribute to continued reliance on informal providers and uncertified formal providers.

These findings suggest that the legal right to abortion is not a reality for the majority of women in our sample in Rajasthan. Women in the study sample clearly have strong desires to meet their reproductive intentions. Existing methods of family planning and abortion services, however, are not meeting their needs. Public information campaign to educate women, their spouses and other family members about the legal right to abortion and efforts to revise the MTP Act are imperative if access to abortion services is to improve. 


\section{Introduction}

\section{Background}

The Medical Termination of Pregnancy (MTP) Act of 1971, which permits abortion for a broad range of social and medical reasons, greatly liberalised access to pregnancy termination in India. Women in India are entitled to abortions when the mother's life is at risk or when her physical or mental health is compromised. Women are also permitted to terminate pregnancies from rape or ones that will result in the birth of a child with physical or mental abnormalities. Married women who experience contraceptive failures may also legally obtain abortions. Abortions may be performed upto 20 weeks of gestation and no spousal consent is required by law, although guardian consent is required for women under 18 years of age. (Government of India 1971).

The MTP Act, together with its associated Rules and Regulations, also specifies both where abortions may be offered and who may perform them. Allopathic government facilities at the primary health centre level or above and private facilities that have received government certification may provide abortion services. Doctors practising modern allopathic medicine who are either trained in obstetrics and gynaecology or have undergone a governmentsanctioned training in pregnancy termination may legally provide abortions. According to the MTP Act, providers trained in Indian systems of medicine, nurses and midwives are not permitted to provide abortions (Government of India 1971).
While the number of certified abortion facilities has increased significantly from 1,877 in $1972-76$ to 9,467 in 1997 (Khan et al 1999) and the number of certified providers has grown as well, access to safe abortion services continues to be limited for the vast majority of women in the country, particularly in poor and rural areas. For example, while the relatively well-off state of Maharashtra has ten percent of the country's population and one-fifth of all certified facilities nationwide, the economically disadvantaged state of Bihar, also with approximately ten percent of the national population, has only one percent of certified facilities (Khan et al 1999). Certified facilities, particularly at lower levels of the health system, are often staffed by non-gynaecologists, but with only 240 recognised abortion-training centres nationwide, such doctors do not have adequate opportunities to be certified (Khan et al 1999).

Even when certified facilities and/or providers are available, important problems in the quality of abortion care exist. Many women experience caustic, judgemental and, in some cases, inhumane treatment from providers (Barua 2002; Ramachandar and Pelto 2002). Similarly, coercive contraception following abortion is not uncommon (Gupta 1993; Gupte et al 1997; Ramachandar and Pelto 2002). Other postabortion services, including counselling regarding signs of possible complications, however, are often absent altogether (Barua 2002; Johnston et al 2001; Khan et al 1999). 
Not surprisingly then, most abortions - upto 90 percent of the annual estimated six million abortions_-continue to be performed illegally, either at uncertified facilities and/or by uncertified providers (Chhabra and Nuna 1994). While some of these illegal abortions are safe, many are unsafe and abortionrelated morbidity and mortality remain significant in India. A hospital-based study conducted in Delhi found that all women presenting with illegal abortions had septic shock and pelvic inflammatory disease, and almost one-third required blood transfusions (Sood et al 1995). In a community-based study conducted in rural Maharashtra, over two-thirds of respondents said they experienced atleast one post-abortion problem that was severe enough to affect routine household work and nearly six percent reported symptoms suggestive of sepsis (Ganatra 2000). While estimates of the proportion of all maternal deaths due to abortion range from five to 20 percent depending on the study methods and population sample (Ganatra et al 1998; Johnston 2002; Sood et al 1995), the Indian Survey of Causes of Death attributes nearly 18 percent of maternal deaths nationwide to abortionrelated causes (Johnston 2002).

Available data suggest that the situation is particularly poor in the less-developed states of north India, including in Rajasthan, where this study took place. Rajasthan has high rates of unwanted fertility and unmet need for family planning, coupled with low contraceptive prevalence rates (IIPS and ORC Macro 2000)_factors that taken together suggest that the demand for abortion is likely to be high. Yet, with a per capita availability of legal abortion services of one per 157,354 individuals, access to safe abortion in Rajasthan is limited (Johnston 2002). One study suggests that nearly all the estimated 352,000 annual induced abortions that take place in the state are performed illegally by uncertified medical or nonmedical practitioners (Chhabra and Nuna 1994). Another study found that dais, followed by female paramedical staff, such as auxiliary nurse midwives and lady health workers, perform the majority of abortions in Rajasthan (ICMR 1989). Thus, by implication, Rajasthan is among the states in India where increased access to safe abortion services is most urgently needed.

Recognising this situation, Parivar Seva Sanstha, an Indian non-governmental reproductive health service provider, launched an initiative to prevent and respond to unwanted pregnancy in Rajasthan in early 2001. Their intervention focuses on increasing access to safe, affordable and high-quality family planning and abortion services, and conducting community outreach to inform men, women and providers about the availability of such services. As a complement to these service-delivery activities, the Population Council undertook a programme of research on unwanted pregnancy and induced abortion in Rajasthan.

The Council's programme was comprised of both qualitative and quantitative studies and was intended to provide a multi-faceted picture of the on-theground realities related to unwanted pregnancy and abortion in Rajasthan. The community-based survey of men and women described in this report is among the studies conducted as part of that programme of research.

\section{Study objectives}

The Population Council and the Centre for Operations Research and Training collaborated on a 
community-based survey of unwanted pregnancy and induced abortion in six districts of Rajasthan.

As community-based data on abortion in India are particularly limited, the study was designed to add to our understanding of the number of women who obtain abortions, as well as the motivations for and circumstances in which women practise abortion. The specific objectives of the study were to:

- Estimate levels of unwanted pregnancy and induced abortion;

- Document the experiences of women undergoing abortions, including why, where and how they obtain abortions; and

- Measure knowledge of abortion legislation and attitudes towards abortion law, risks and services among both men and women.
Taken together with a qualitative study and a situation analysis of abortion providers conducted as part of the Council's programme of research on unwanted pregnancy and induced abortion in Rajasthan (Barge et al 2004; Elul et al 2004), it is hoped that findings from this study will provide a more comprehensive picture of the abortion situation in Rajasthan.

\section{Sampling}

A cross-sectional community-based survey of evermarried women aged $15-44$ years $(n=3,266)$ and a sub-sample of these women's husbands $(\mathrm{n}=602)$ was conducted in six districts of Rajasthan. The six study districts-Alwar, Bhilwara, Bikaner, Karauli, Pali and Tonk-were purposively sampled to match the areas where Parivar Seva Sanstha is implementing its activities. A few key indicators of the sampled districts are displayed in Table 1.1.

Table 1.1

Summary socio-demographic and health statistics for sampled districts and for the state of Rajasthan

\begin{tabular}{|c|c|c|c|c|c|c|c|}
\hline District & Alwar & Bhilwara & Bikaner & Karauli & Pali & Tonk & Rajasthan \\
\hline Population & $2,990,862$ & $2,009,516$ & $1,673,562$ & $1,205,631$ & $1,819,201$ & $1,211,343$ & $56,473,122$ \\
\hline Density & 357 & 192 & 61 & 218 & 147 & 168 & 165 \\
\hline \multicolumn{8}{|l|}{ Literacy rate (\%) } \\
\hline Overall & 62.5 & 51.1 & 57.5 & 64.6 & 54.9 & 52.4 & 61.0 \\
\hline Female & 44.0 & 33.5 & 42.6 & 45.4 & 36.7 & 32.3 & 44.3 \\
\hline Child sex ratio & 888 & 951 & 915 & 876 & 927 & 922 & 909 \\
\hline Contraceptive use (\%) & 40.4 & 32.9 & 40.6 & 25.6 & 34.2 & 36.0 & 33.2 \\
\hline Institutional deliveries (\%) & 15.9 & 17.9 & 25.0 & 26.5 & 14.5 & 13.4 & 19.8 \\
\hline \multicolumn{8}{|l|}{ Density: Population per square kilometer. } \\
\hline \multicolumn{8}{|l|}{ Sex ratio: Number of girls to boys aged $0-6}$. \\
\hline Population, density, sex ratio, literacy & nsus of Ind & & & & & & \\
\hline
\end{tabular}


Multi-stage stratified cluster sampling was used to select respondents across these six districts. In coordination with the urban and peri-urban focus of Parivar Seva Sanstha's activities, the sample was restricted to district headquarters and villages and towns lying within a 25-kilometre radius of the district headquarters, as well as one pre-selected town per district and villages lying within a five-kilometre radius of those towns. The sample was stratified by geographic area, with urban areas over-sampled to improve the reliability of the estimates for those heterogeneous localities. In the next stage of sampling, depending on the type of administrative unit being sampled (district headquarter or town vs. village), wards and then quadrants (district headquarter or town), or quadrants only (village) were randomly selected from a complete list of primary sampling units. As census maps were unavailable, a listing of 200 consecutive households, beginning at a randomly selected spot, was completed in each randomly selected primary sampling unit and served as the sampling frame for both female and male respondents.

For the female sample, 30 urban and 20 rural households were systematically selected from the sampling frame in each primary sampling unit. All ever-married women aged 15-44 residing in a selected household were invited to participate in the survey. Women who refused to participate in the study were not replaced by other respondents. If women were unavailable to be interviewed when initially approached by the interviewers, upto three additional visits were made in an attempt to conduct the interview.
For the male sample, five men in each urban primary sampling unit and three men in each rural primary sampling unit were systematically selected from the larger sample of households in which women were interviewed. In contrast to the approach used to select female respondents, if men refused to participate or were unavailable after repeated visits by the study team, the next household in which a woman had been interviewed was selected from the sampling frame for that primary sampling unit and her husband invited to participate.

\section{Data collection and analysis}

All data collection occurred between September and December 2001. Three structured instruments-a household questionnaire, a woman's questionnaire, and a man's questionnaire-were used to collect data from female and male respondents in face-to-face interviews.

- Household questionnaire: The household questionnaire was designed to gather demographic information on all permanent household members, as well as information on household socio-economic status. In each household, the head or a representative was asked to complete the questionnaire.

- Woman's questionnaire: In addition to collecting basic background data from female respondents, this instrument was used to gather information from women about their reproductive and abortion experiences, knowledge of abortion legislation, attitudes towards abortion and preferences for abortion providers. 
Information on women's reproductive experiences was obtained using a detailed pregnancy history which documented all pregnancies, whether or not they resulted in live births. Women were first asked to enumerate each pregnancy that resulted in a live birth as we believed that women would be most forthcoming about pregnancies that resulted in live births, even if the child subsequently died. For each reported birth, respondents were queried about the intendedness of that child at the time of conception. The questions on pregnancy intentions served as a segue to ask whether any attempt had been made to end that pregnancy as a similar approach had yielded high reports of abortion attempts in some settings (Huntington et al 1993; Huntington et al 1996). Using the information on live births, the interviewer then constructed birth intervals and asked about pregnancies that did not result in a live birth in each interval. For example, starting with the interval closest to the survey, the interviewer asked, "Did you have any pregnancies that lasted only a short time between now and the birth of [name], your last child?" For each such reported pregnancy, women were again asked if the pregnancy had been intended and if abortion had been attempted and successful. Women were asked the same set of questions for each birth interval. In addition to those questions on abortions, women also were asked directly whether they ever had any pregnancies that lasted even for a few days or weeks, and if so, the timing and outcome of such pregnancies.
- Man's questionnaire: In addition to collecting basic background data from male respondents, this instrument was used to gather information about men's knowledge of abortion legislation, attitudes towards abortion, and preferences for abortion providers.

The study instruments were drafted in English and translated into Hindi. The woman's and man's instruments were pre-tested in a clinic setting in the city of Udaipur, a district headquarter in Rajasthan that was not included in our sampling frame, as well as at the community level in a village approximately 15 kilometres from Udaipur. The instruments were modified following the pre-test.

A team of 24 female and seven male investigators were recruited from the study area for data collection. An intensive one-week study training, which covered basic reproductive health concepts, the sampling methodology and the study instruments, was conducted by staff from the Centre for Operations Research and Training and the Population Council. Interviews were conducted in Hindi and the local language. Participation in this study was voluntary and uncompensated. All respondents gave oral informed consent before being interviewed. Interviews with men and women were conducted separately, and information collected from one spouse was not shared with the other spouse. The data were entered and cleaned using Fox Pro and transferred to STATA 8.0 for analysis.

Due to the purposive selection of the study districts and sampling areas, the results presented in this report are unweighted and are not representative 
of the sampled districts or the state of Rajasthan.

Data are disaggregated by residence area, and in some cases, by gender. Because the male sample is approximately one-fifth the size of the female sample, no comparisons are made between husbands and wives per se. This report presents only the main findings of the study. More detailed analyses have been conducted and are available upon request.

\section{Sample coverage}

Table 1.2 provides the response rates for the households, women and men sampled. A total of 3,781 households were approached to participate in the study, and household questionnaires were completed in 3,703 of them, yielding a household response rate of 98 percent. In the participating 3,703 households, 3,682 eligible women (ever-married

Table 1.2

Sample coverage

\begin{tabular}{|c|c|c|c|}
\hline & Urban & Rural & Total \\
\hline \multicolumn{4}{|l|}{ Households (n) } \\
\hline Contacted & 2,343 & 1,438 & 3,781 \\
\hline Completed & 2,291 & 1,412 & 3,703 \\
\hline Not at home & 36 & 23 & 59 \\
\hline Refused & 11 & - & 11 \\
\hline Partially completed & - & 1 & 1 \\
\hline Other & 5 & 2 & 7 \\
\hline Response rate (\%) & 97.8 & 98.2 & 97.9 \\
\hline \multicolumn{4}{|l|}{ Eligible women (n) } \\
\hline Contacted & 2,343 & 1,438 & 3,781 \\
\hline Completed & 1,969 & 1,297 & 3,266 \\
\hline Not at home & 190 & 141 & 331 \\
\hline Refused & 37 & 5 & 42 \\
\hline Partially completed & 18 & 11 & 29 \\
\hline Other & 9 & 5 & 14 \\
\hline Response rate (\%) & 88.6 & 88.9 & 88.7 \\
\hline \multicolumn{4}{|l|}{ Eligible husbands (n) } \\
\hline Contacted & 389 & 217 & 606 \\
\hline Completed & 387 & 215 & 602 \\
\hline Not at home & - & - & - \\
\hline Refused & - & - & - \\
\hline Partially completed & 2 & 2 & 4 \\
\hline Other & 2 & - & 一 \\
\hline Response rate (\%) & 99.5 & 99.1 & 99.3 \\
\hline
\end{tabular}


women between 15 and 44 years of age) were identified and interviews completed with 3,266 of them, yielding a response rate of 89 percent for the female sample. Interviews with the remaining 416 women were not completed as the women were either not at home in spite of repeated visits $(\mathrm{n}=331)$, refused to participate $(n=42)$, started the interview but were unable to complete it $(n=29)$, or had a disability or illness that precluded the conduct of the interview $(\mathrm{n}=14)$. Of the 606 husbands contacted, 602 completed interviews, yielding a response rate of 99 percent for the male sample.

\section{About this report}

This report has five main sections:

- Chapter 2 describes the characteristics of the households sampled and the male and female respondents.

- Chapter 3 provides information on reproductive outcomes as reported by women. Levels of unwanted pregnancy and induced abortion are included in this chapter.

- Chapter 4 documents the abortion experiences among the women reporting abortions in the five years preceding the survey. Detailed information regarding abortion decision-making, pathways and provider selection, as well as post-abortion complications and family planning use is presented.

- Chapter 5 examines both male and female respondents' knowledge of and attitudes towards the legality of abortion. This chapter also describes men and women's perceptions of the risks associated with abortion, their preferences for abortion facilities and providers, as well as their familiarity with sex-selective abortion.

- Chapter 6 summarises the findings of this study and offers policy and programmatic recommendations to ensure greater access to safe abortion services in Rajasthan. 


\section{Characteristics of Households and Respondents}

This section presents the socio-demographic profile of the study households and individual respondents.

\section{Characteristics of households}

The majority of households sampled were Hindu (83 percent) (Table 2.1). Muslim households accounted for a large minority (14 percent) of the sample, particularly in urban areas (18 percent).

Approximately two-thirds of households belonged to a scheduled caste or tribe, or other backward caste.

Each household in both urban and rural areas averaged six members.

\section{Table 2.1}

Characteristics of households (\%)

\begin{tabular}{|c|c|c|c|}
\hline & Urban & Rural & Total \\
\hline \multicolumn{4}{|l|}{ Religion } \\
\hline Hindu & 77.4 & 93.0 & 83.3 \\
\hline Muslim & 18.1 & 6.4 & 13.6 \\
\hline Christian & - & 0.1 & 0.1 \\
\hline Sikh & 0.6 & 0.4 & 0.5 \\
\hline Jain & 3.9 & 0.1 & 2.5 \\
\hline \multicolumn{4}{|l|}{ Caste/tribe } \\
\hline Scheduled caste & 19.2 & 27.5 & 22.4 \\
\hline Scheduled tribe & 2.2 & 13.4 & 6.5 \\
\hline Other backward caste & 35.7 & 38.4 & 36.7 \\
\hline Other caste & 42.7 & 19.8 & 34.0 \\
\hline Do not know & 0.2 & 0.8 & 0.5 \\
\hline \multicolumn{4}{|l|}{ Number of usual household members } \\
\hline $1-2$ & 9.6 & 10.1 & 9.8 \\
\hline $3-5$ & 42.2 & 39.1 & 41.0 \\
\hline $6-10$ & 41.5 & 43.8 & 42.3 \\
\hline$\geq 11$ & 6.8 & 7.0 & 6.9 \\
\hline Mean number of usual household members & 5.9 & 6.0 & 5.9 \\
\hline \multicolumn{4}{|l|}{ Standard of living index } \\
\hline Low & 18.7 & 52.2 & 31.5 \\
\hline Medium & 38.2 & 35.7 & 37.2 \\
\hline High & 43.1 & 12.1 & 31.3 \\
\hline Households (n) & 2,291 & 1,412 & 3,703 \\
\hline
\end{tabular}


Following the National Family Health Survey-2 methodology (IIPS and ORC Macro 2000), a standard of living index was calculated for each household based on the ownership of durable goods. By this measure, over half ( 52 percent) of the rural households sampled were in the low standard of living category, compared to 19 percent of urban households. Similarly, nearly half ( 43 percent) of the urban households fell in the high standard of living category, compared to 12 percent in rural areas.

\section{Characteristics of female respondents}

Table 2.2 presents the socio-economic characteristics of the 3,266 ever-married women interviewed. On average, female respondents were 30 years of age, and nearly all (97 percent) were married at the time of the survey. Literacy levels and educational attainment varied significantly by place of residence. While 15 percent of the urban women had studied atleast upto the higher secondary level, only two percent of the rural women were similarly educated. Approximately two-fifths (42 percent) of the women were working at the time of the survey. However, more rural women (67 percent) than urban women (26 percent) were working at the time of the survey. The vast majority of female respondents were Hindu (83 percent), particularly in rural areas (94 percent). While nearly two-thirds of all the women interviewed belonged to a scheduled caste or tribe, or other backward caste,
41 percent of the urban sample belonged to other (upper) castes. On average, women in the study were married by 15.2 years of age (well below the legal age of marriage in India, which is 18 years), and began residing with their spouses approximately two and a half years later. The average woman interviewed had her first pregnancy after about two years of co-habitating with her spouse, at 19.6 years of age. Nearly 90 percent of all women, whether residing in an urban or rural area, had atleast one living child at the time of the survey. On average, women reported 1.6 living sons and 1.5 living daughters.

\section{Characteristics of male respondents}

The demographic profile of the 602 men interviewed is presented in Table 2.3. On average, male respondents were 34 years of age. As with the female respondents, there were significant geographic differences in literacy levels and educational attainment. The proportion of male respondents with no education was three times higher in rural (37 percent) than in urban (12 percent) areas. Almost all of the male respondents (98 percent) were working at the time of the survey. The religious and caste composition of male respondents was similar to that of female respondents, with the vast majority belonging to the Hindu religion ( 83 percent) and lower castes (scheduled caste: 23 percent; scheduled tribe: 7 percent; other backward caste: 31 percent). 
Table 2.2

Characteristics of female respondents (\%)

\begin{tabular}{|c|c|c|c|}
\hline & Urban & Rural & Total \\
\hline \multicolumn{4}{|l|}{ Age in years } \\
\hline $15-19$ & 5.8 & 10.4 & 7.7 \\
\hline $20-24$ & 17.8 & 23.3 & 20.0 \\
\hline $25-29$ & 21.5 & 22.1 & 21.6 \\
\hline $30-34$ & 21.4 & 18.8 & 20.4 \\
\hline $35-39$ & 18.5 & 13.6 & 16.6 \\
\hline $40-44$ & 14.9 & 11.8 & 13.7 \\
\hline Mean age (years) & 30.6 & 28.9 & 29.9 \\
\hline \multicolumn{4}{|l|}{ Marital status } \\
\hline Currently married & 96.6 & 96.8 & 96.7 \\
\hline Separated/deserted & 0.9 & 0.6 & 0.7 \\
\hline Divorced & 0.3 & - & 0.2 \\
\hline Widowed & 2.2 & 2.6 & 2.4 \\
\hline \multicolumn{4}{|l|}{ Literacy } \\
\hline Literate & 54.0 & 17.1 & 39.3 \\
\hline Illiterate & 46.0 & 82.9 & 60.7 \\
\hline \multicolumn{4}{|l|}{ Education level } \\
\hline None & 46.6 & 84.3 & 61.5 \\
\hline Less than primary & 3.1 & 3.5 & 3.3 \\
\hline Upto primary & 7.6 & 5.3 & 6.7 \\
\hline Upto middle & 14.6 & 3.8 & 10.3 \\
\hline Upto high school & 12.8 & 1.6 & 8.4 \\
\hline Upto higher secondary & 5.9 & 0.8 & 3.9 \\
\hline Upto graduate & 4.8 & 0.5 & 3.1 \\
\hline Postgraduate or beyond & 4.6 & 0.2 & 2.8 \\
\hline \multicolumn{4}{|l|}{ Working status } \\
\hline Working & 25.6 & 67.2 & 42.1 \\
\hline Non-working & 74.4 & 32.8 & 57.9 \\
\hline \multicolumn{4}{|l|}{ Religion } \\
\hline Hindu & 75.9 & 93.5 & 82.9 \\
\hline Muslim & 19.7 & 6.2 & 14.3 \\
\hline Other & 4.4 & 0.3 & 2.8 \\
\hline
\end{tabular}


Table 2.2

Characteristics of female respondents (\%) (continued)

\begin{tabular}{|c|c|c|c|}
\hline & Urban & Rural & Total \\
\hline \multicolumn{4}{|l|}{ Caste } \\
\hline Scheduled caste & 19.1 & 27.9 & 22.6 \\
\hline Scheduled tribe & 2.3 & 13.0 & 6.5 \\
\hline Other backward caste & 37.0 & 40.6 & 38.4 \\
\hline Other caste & 41.4 & 17.6 & 32.0 \\
\hline Do not know & 0.2 & 0.9 & 0.5 \\
\hline \multicolumn{4}{|c|}{$\begin{array}{l}\text { Mean age at marriage, co-habitation and first } \\
\text { pregnancy (years) }\end{array}$} \\
\hline Marriage & 16.6 & 13.0 & 15.2 \\
\hline Co-habitation & 18.2 & 17.2 & 17.8 \\
\hline First pregnancy & 19.6 & 19.0 & 19.6 \\
\hline \multicolumn{4}{|l|}{ Children ever born } \\
\hline Had atleast one child ever born & 88.6 & 89.0 & 88.7 \\
\hline Mean number of sons ever born & 1.6 & 1.8 & 1.7 \\
\hline Mean number of daughters ever born & 1.4 & 1.6 & 1.5 \\
\hline \multicolumn{4}{|l|}{ Living children } \\
\hline Had atleast one living child & 88.0 & 87.9 & 88.0 \\
\hline Mean number of living sons & 1.6 & 1.7 & 1.6 \\
\hline Mean number of living daughters & 1.4 & 1.5 & 1.5 \\
\hline Women (n) & 1,969 & 1,297 & 3,266 \\
\hline
\end{tabular}


Table 2.3

Characteristics of male respondents (\%)

\begin{tabular}{|c|c|c|c|}
\hline & Urban & Rural & Total \\
\hline \multicolumn{4}{|l|}{ Age in years } \\
\hline $15-19$ & 0.3 & 0.5 & 0.3 \\
\hline $20-24$ & 8.3 & 14.0 & 10.3 \\
\hline $25-29$ & 18.1 & 21.8 & 19.4 \\
\hline $30-34$ & 22.5 & 18.6 & 21.1 \\
\hline $35-39$ & 22.6 & 15.8 & 20.3 \\
\hline $40-44$ & 13.7 & 17.2 & 15.0 \\
\hline $45-49$ & 10.6 & 9.8 & 10.3 \\
\hline$\geq 50$ & 3.9 & 2.3 & 3.3 \\
\hline Mean age (years) & 35.0 & 33.3 & 34.4 \\
\hline \multicolumn{4}{|l|}{ Marital status } \\
\hline Currently married & 100.0 & 100.0 & 100.0 \\
\hline Separated/deserted & - & - & - \\
\hline Divorced & - & - & - \\
\hline Widowed & - & - & - \\
\hline \multicolumn{4}{|l|}{ Literacy } \\
\hline Literate & 88.6 & 64.2 & 79.9 \\
\hline Illiterate & 11.4 & 35.8 & 20.1 \\
\hline \multicolumn{4}{|l|}{ Education level } \\
\hline None & 12.1 & 36.7 & 20.9 \\
\hline Less than primary & 5.7 & 5.6 & 5.6 \\
\hline Upto primary & 6.5 & 9.3 & 7.5 \\
\hline Upto middle & 16.8 & 20.5 & 18.1 \\
\hline Upto high school & 23.0 & 13.0 & 19.4 \\
\hline Upto higher secondary & 15.0 & 5.6 & 11.6 \\
\hline Upto graduate & 11.1 & 4.7 & 8.8 \\
\hline Postgraduate or beyond & 9.8 & 4.7 & 8.0 \\
\hline \multicolumn{4}{|l|}{ Working status } \\
\hline Working & 97.2 & 98.1 & 97.5 \\
\hline Non-working & 2.8 & 1.9 & 2.5 \\
\hline
\end{tabular}


Table 2.3

Characteristics of male respondents (\%) (continued)

\begin{tabular}{|l|c|c|c|}
\hline & Urban & Rural & Total \\
\hline Religion & & & \\
\hline Hindu & 77.5 & 92.5 & 82.8 \\
Muslim & 17.1 & 7.0 & 13.5 \\
\hline Other & 1.3 & 0.5 & 1.0 \\
\hline No religion & 4.1 & 0.0 & 2.7 \\
\hline Caste & & & \\
Scheduled caste & & & 23.4 \\
Scheduled tribe & 19.4 & 30.7 & 7.0 \\
\hline Other backward caste & 2.8 & 14.4 & 31.2 \\
\hline Other caste & 30.0 & 33.5 & 38.0 \\
\hline Do not know & 47.5 & 20.9 & 0.3 \\
\hline Men (n) & 0.3 & 0.5 & $\mathbf{6 0 2}$ \\
\hline
\end{tabular}




\section{Prevalence of Unwanted Pregnancy and Induced Abortion}

This chapter presents data on levels of unwanted pregnancy and induced abortion. The structure of our dataset allows us to examine these issues from several different angles, and thus we refer alternately to women, pregnancies and live births as denominators in this chapter.

\section{Unwanted pregnancy levels}

Eleven percent of the 3,108 pregnancies reported in the five years preceding the survey were unwanted (Figure 3.1). The number of unwanted pregnancies was greater in urban areas (15 percent) than in rural areas ( 6 percent). Unwanted pregnancies accounted for six percent of all live births and 70 percent of all induced abortions in the five years preceding the survey (data not shown). As indicated in

Figure 3.2, unwanted pregnancies were primarily either not wanted at all ( 63 percent) or wanted at a later date (27 percent). Only a few pregnancies were considered unwanted because the mother (or other family members) desired a child of a different sex (4 percent).

\section{Induced abortion levels}

A fairly significant proportion of women in our sample-13 percent—had undergone an abortion atleast once by the time of the study (Figure 3.3). As pregnancies are subject to recall bias, particularly

Figure 3.1

Pregnancy intentions

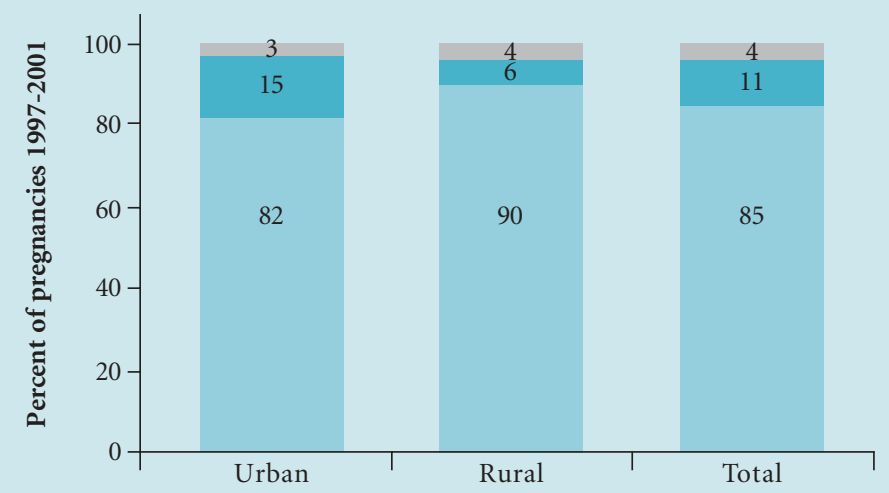

Wanted

Unwanted

Never thought of 


\section{Figure 3.2}

Reasons for unwanted pregnancy

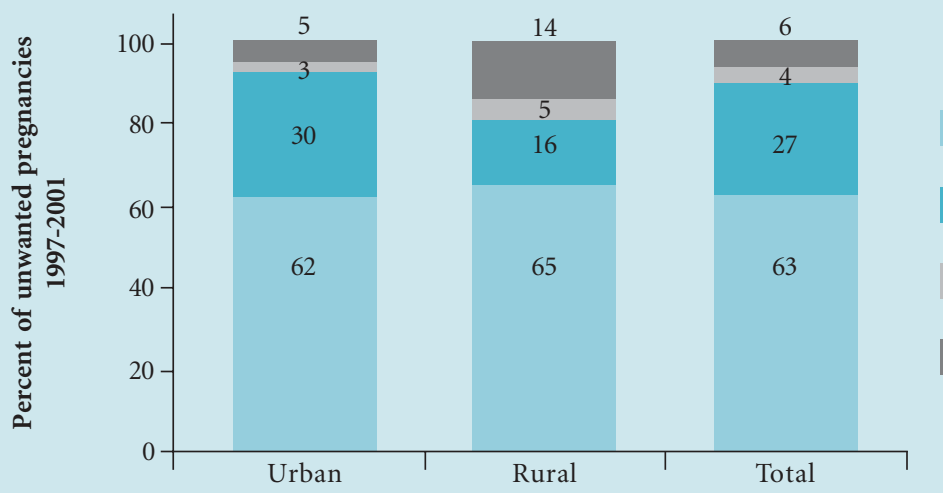

Did not want more children

Pregnancy ill-timed

Sex of the foetus

Other

\section{Figure 3.3}

Prevalence of induced abortion

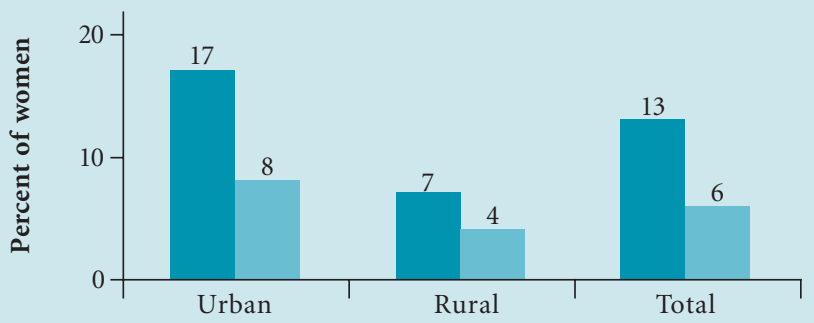

Ever had

$1997-2001$

the further back in time they occur, we also present the figures for the five years preceding the survey, during the period of 1997-2001 (Figure 3.3): Six percent of women deliberately terminated atleast one pregnancy in the five years preceding the survey, with more urban (8 percent) than rural ( 4 percent) women reporting atleast one induced abortion in that time period.
As Figure 3.4 shows, differentials in the prevalence of abortion appear to be driven by socio-economic factors. Urban women, those who are literate or reside in a household with a higher standard of living have considerably higher rates of ever having an abortion compared to rural women, those who are illiterate or reside in households with a lower standard of living. 


\section{Figure 3.4}

Prevalence of induced abortion by background characteristics

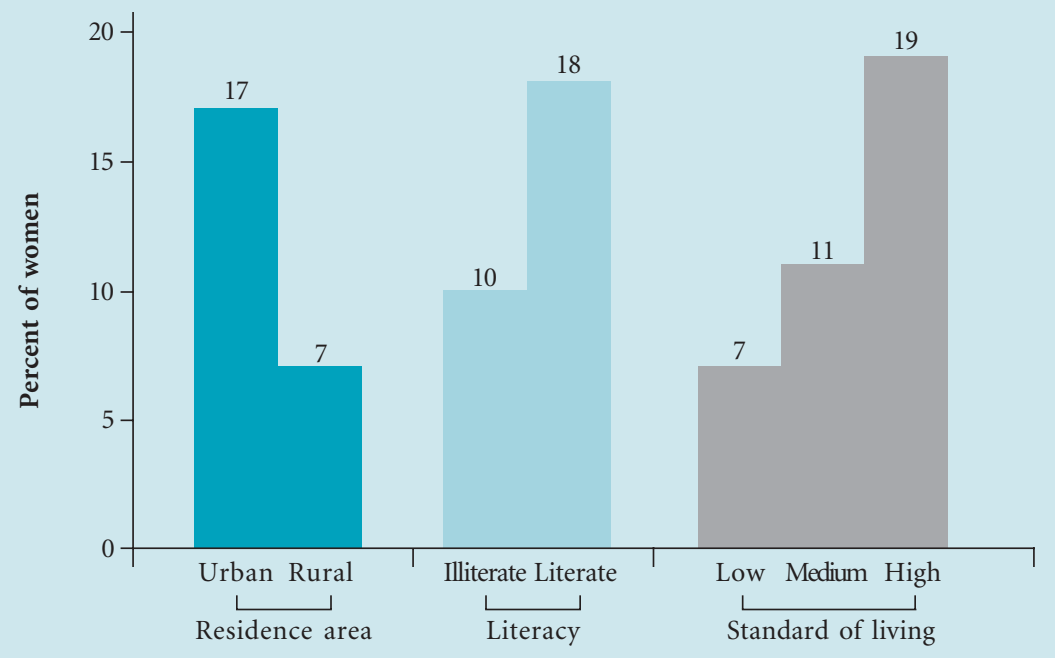

Abortion data are often portrayed as abortion ratios - the number of abortions per 100 live births-in order to provide a better idea of the relative difference in possible outcomes once a woman is pregnant. As Figure 3.5 shows, according to our data, women had five abortions for every 100 live births that they ever had. Urban women ( 7 abortions per 100 live births) were approximately three times as likely as rural women (2 abortions per 100 live births) to obtain induced abortions once pregnant. When we include only the pregnancies from the more recent period of 1997 2001, we find that nine abortions occurred for every 100 live births, with virtually no difference observed in urban and rural areas.

Figure 3.6 compares the induced abortion ratios using all pregnancies from our study with others available for the state of Rajasthan, including those from the 1989-99 National Family Health Survey and from a 1983-85 study conducted by the Indian Council of Medical Research. As the sampling and time frames differ across the three studies, the results are only suggestive, but nonetheless indicate that the numbers for our study are consistently higher than those obtained in other household surveys in Rajasthan. 


\section{Figure 3.5}

Induced abortion ratios

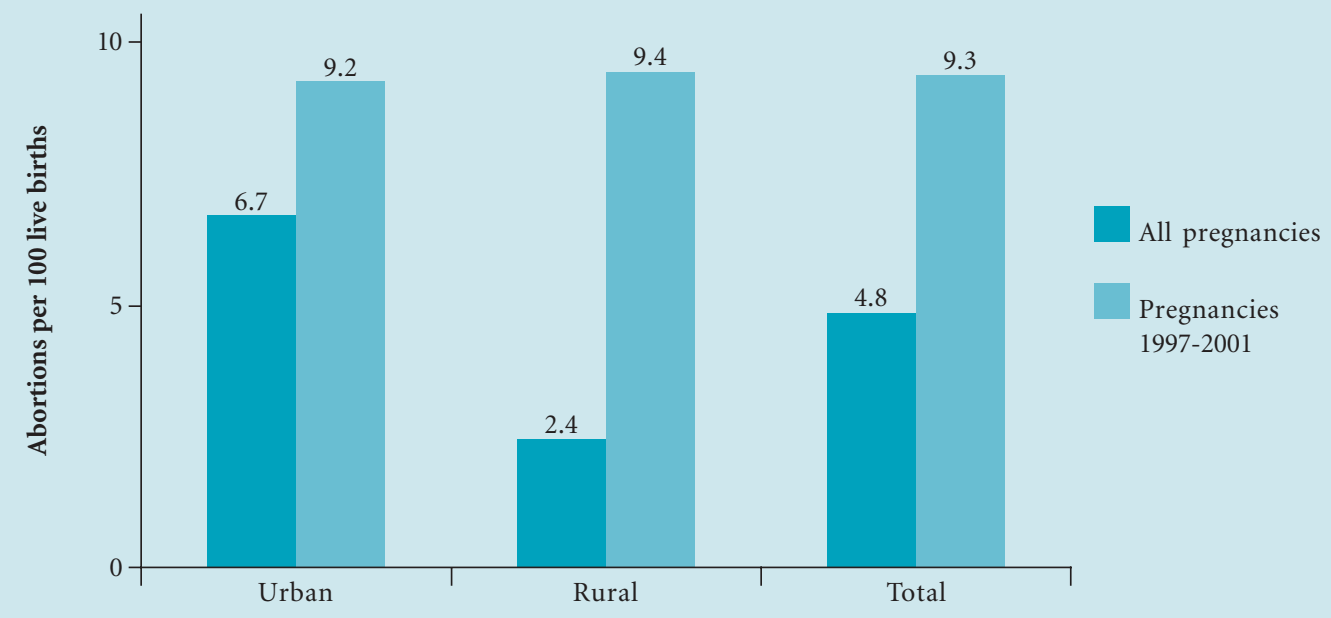

Figure 3.6

Comparison of induced abortion ratios

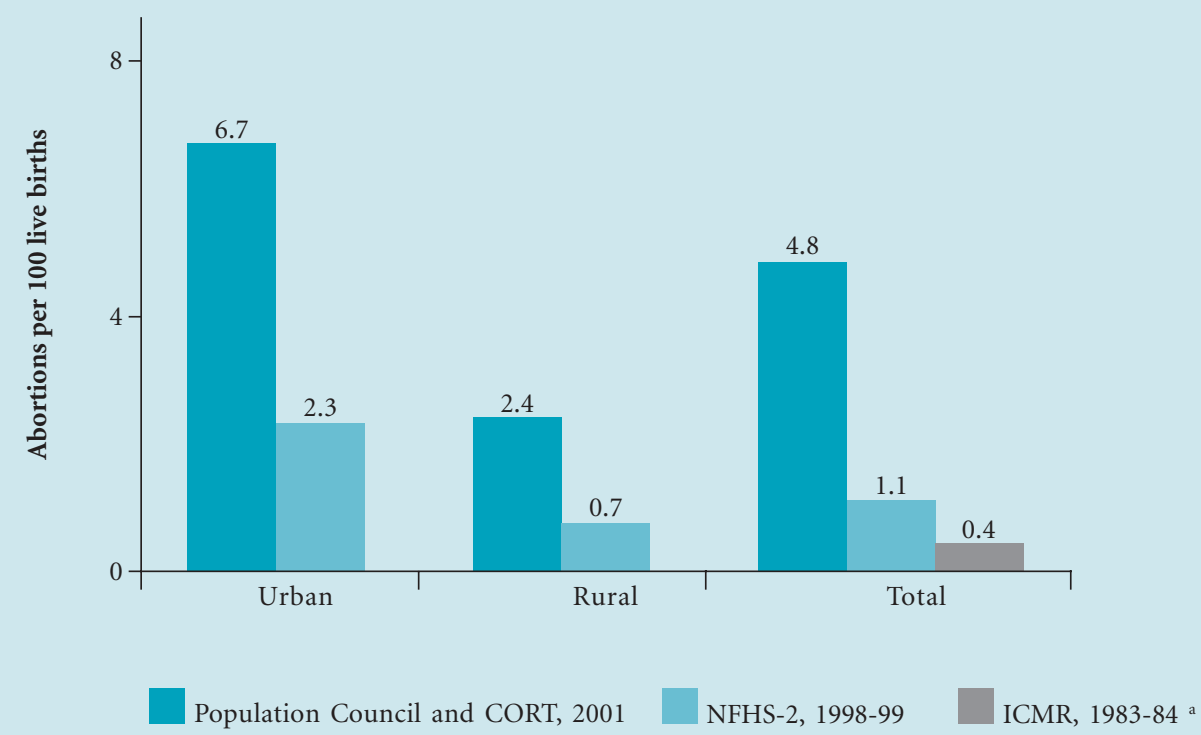

${ }^{a}$ Data only available for total sample. 
Abortion ratios for the period from 1978 to 2001 are presented in Figure 3.7. Overall, the number of abortions per 100 live births has increased substantially and steadily since the early 1990s, when women had about three induced abortions per 100 live births, to approximately ten years later, in 1999-2001, when women terminated eleven pregnancies for every 100 live births. While abortions began to account for a greater and greater proportion of pregnancy outcomes in urban areas as early as the mid-1980s, the relative increase in abortions to live births in rural areas did not begin until nearly a decade later, in the mid-1990s.

Figure 3.7

Induced abortion ratios, 1978-2001

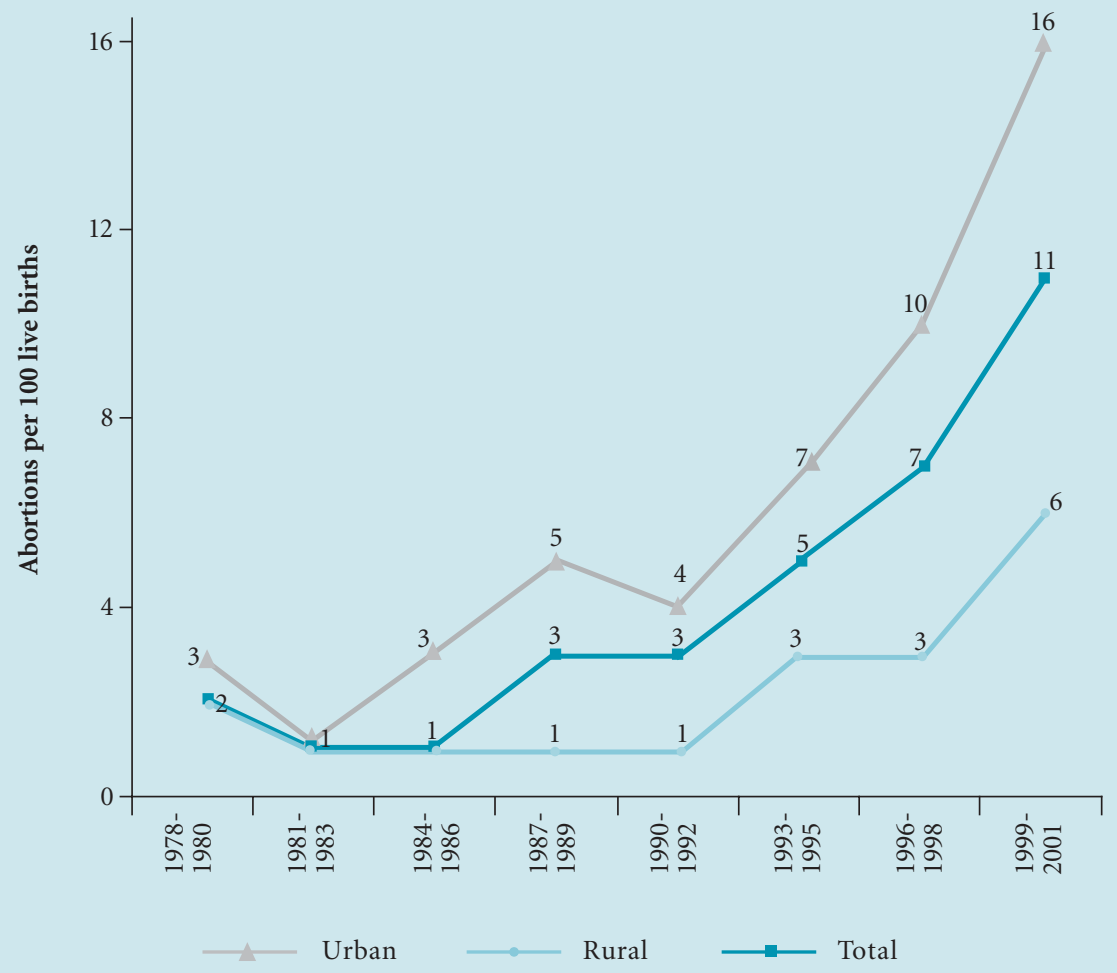




\section{CHAPTER 4}

\section{Abortion Experiences}

In this chapter, we present detailed data on the experiences of the 203 women who reported atleast one successful induced abortion in the five years preceding the survey, during the period of 1997-2001. If women reported more than one abortion in that period, information is presented for their last abortion.

\section{Reasons for abortion and abortion decision-making}

Women provided a variety of reasons for terminating their pregnancies (Table 4.1). The majority of women reporting an abortion in the five years preceding the survey indicated that they (59 percent) and/or their spouse (18 percent) had achieved their desired family size and thus did not want any more children. A fair number of women had abortions because their last child was too young (22 percent) or because they were experiencing health problems (20 percent). Only a small number of urban women explicitly mentioned foetal malformation (2 percent) or contraceptive failure ( 2 percent) as the reason for their abortion. While few women (3 percent) reported undergoing

Table 4.1

Reasons for abortion and abortion decision-making (\%)

\begin{tabular}{|c|c|c|c|}
\hline & Urban & Rural & Total \\
\hline \multicolumn{4}{|l|}{ Reasons for abortion ${ }^{\text {a }}$} \\
\hline Limit childbearing, personal desire & 60.4 & 53.1 & 58.6 \\
\hline Limit childbearing, spouse's desire & 20.1 & 12.2 & 18.2 \\
\hline Space childbearing & 22.7 & 18.4 & 21.7 \\
\hline Contraceptive failure & 2.6 & - & 2.0 \\
\hline Health problems & 19.5 & 22.4 & 20.2 \\
\hline Female foetus & 1.9 & 4.1 & 2.5 \\
\hline Foetal malformation & 1.3 & 2.0 & 1.5 \\
\hline Other & 5.2 & 4.0 & 5.0 \\
\hline \multicolumn{4}{|l|}{ Involved in decision-making a } \\
\hline Self only & 27.3 & 24.5 & 26.6 \\
\hline Spouse only & 28.6 & 14.3 & 25.1 \\
\hline Self and spouse & 53.9 & 57.1 & 54.7 \\
\hline Other family member(s) & 14.9 & 14.3 & 14.8 \\
\hline Friend(s) & 0.6 & 2.0 & 1.0 \\
\hline Doctor & 11.0 & 18.3 & 12.8 \\
\hline Had induced abortion 1997-2001 (n) & 154 & 49 & 203 \\
\hline
\end{tabular}

${ }^{a}$ May total to more than 100 percent because of multiple responses. 
abortions because they were carrying a female foetus, more rural ( 4 percent) than urban ( 2 percent) women cited this as a reason for their abortion.

As Table 4.1 shows, when asked who participated in making the decision to terminate the pregnancy, most women ( 55 percent), whether residing in urban or rural areas, reported that both partners were involved. About one-quarter of women, however, said that they (27 percent) or their spouse (25 percent) was solely responsible for the decision. Over twice the proportion of urban women (29 percent) than rural women (14 percent) indicated that their spouse had made the decision without their inputs. Other family members played a role in the abortion decisionmaking process approximately 15 percent of the time. Doctors also played an important role in the abortion decision-making process, particularly among rural women (18 percent).

Ten percent of women deliberately concealed their abortions from one or more individuals (Figure 4.1), generally extended family members.

\section{Figure 4.1}

Deliberately concealed abortion

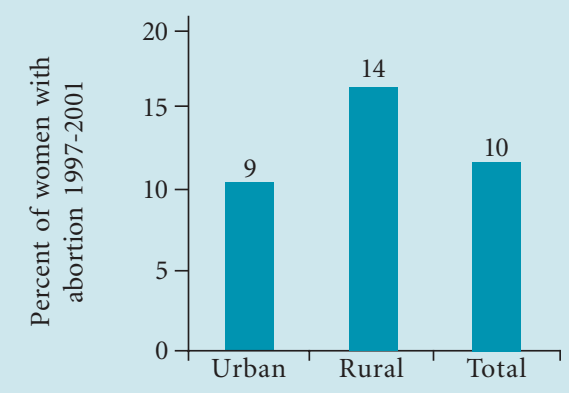

Rural women (14 percent) were more likely than their urban counterparts ( 9 percent) to hide their abortions from atleast one person. As Figure 4.2 shows, husbands were reportedly aware of their wives' abortions 72 percent of the time. Fewer rural (61 percent) than urban (74 percent) women told other family members of their abortions. Similarly, rural women (6 percent) were substantially less likely than urban women (23 percent) to share their abortions with friends.

\section{Gestational age}

As indicated in Figure 4.3, the vast majority of women reported terminating their pregnancies in the late first trimester (70 percent), with the bulk occurring three months after their last menstrual period, corresponding to a gestational age of approximately 13 to 16 weeks ( 42 percent). A significant proportion of rural women (37 percent), however, reportedly had their abortions in the late second trimester, four months after their last menstrual period when their gestational age was about 17 to 20 weeks. A number of urban women (8 percent) — and twice the number as in rural areas (4 percent)—had abortions five months after their last menstrual period, beyond the legal limit of 20 weeks' gestational age.

\section{Treatments and providers}

Our study instrument included several questions to document the pathways women took to terminate their pregnancies. The first of these questions asked women whether they had done anything on their own to provoke their abortions or had sought services from an informal provider. In total, 20 percent of the women who reported successful abortions stated that 
Figure 4.2

Aware of abortion

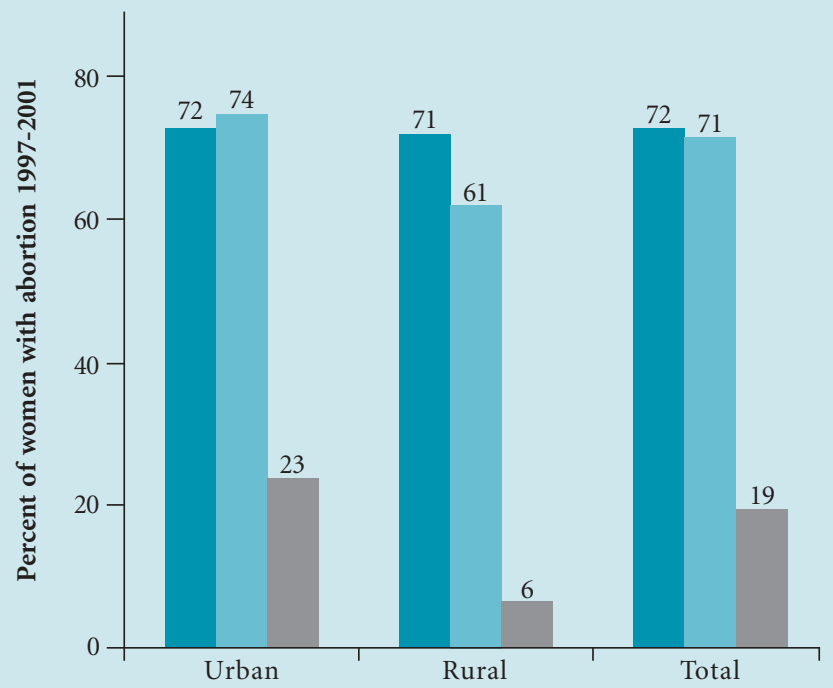

Husband

Other family members(s)

Friend(s)

Figure 4.3

Self-reported gestational age at abortion (months since last menstrual period)

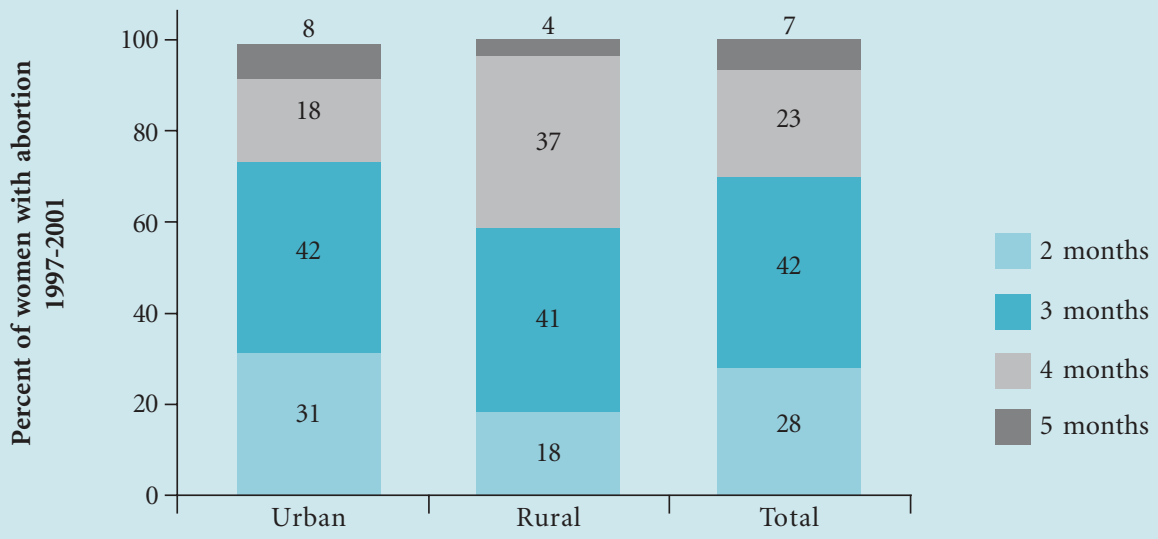


they had indeed taken such action to end their pregnancies (Figure 4.4). Most of these 41 women reportedly used home remedies and/or obtained ayurvedic or allopathic tablets from chemists, vaidhs or other informal providers. Some received massages or other treatments from dais, auxiliary nurse midwives or other female paramedical staff (data not shown). Approximately two-thirds of these 41 women reported that these actions resulted in complete abortions and that they did not go on to seek abortion services from any formal provider (data not shown). For the remaining women, however, these attempts proved unsuccessful and they eventually sought services from a formal provider. Indeed, in total, 89 percent of the 203 women with successful abortions obtained services from a formal provider (Figure 4.4). Data not shown indicates that these women, whether from urban or rural areas, went to an average of 1.1 formal providers to have their pregnancies terminated.

Figure 4.5 displays the types of providers women used for their abortions among those who sought services from a formal provider. Over half of both urban (57 percent) and rural (59 percent) women obtained services from a public-sector provider. While a district hospital doctor was the primary public-sector provider used in both urban (46 percent) and rural (33 percent) areas, a large proportion of rural women (26 percent) sought services from a doctor working in a lower-level publicsector facility. Private-sector doctors also accounted for a significant proportion of the providers used in both urban (43 percent) and rural areas (41 percent).

As shown in Table 4.2, the majority of women selected a specific provider because he/she was a good or popular doctor (40 percent) or their family doctor (35 percent). For 24 percent of rural women, their

Figure 4.4

Abortion pathways

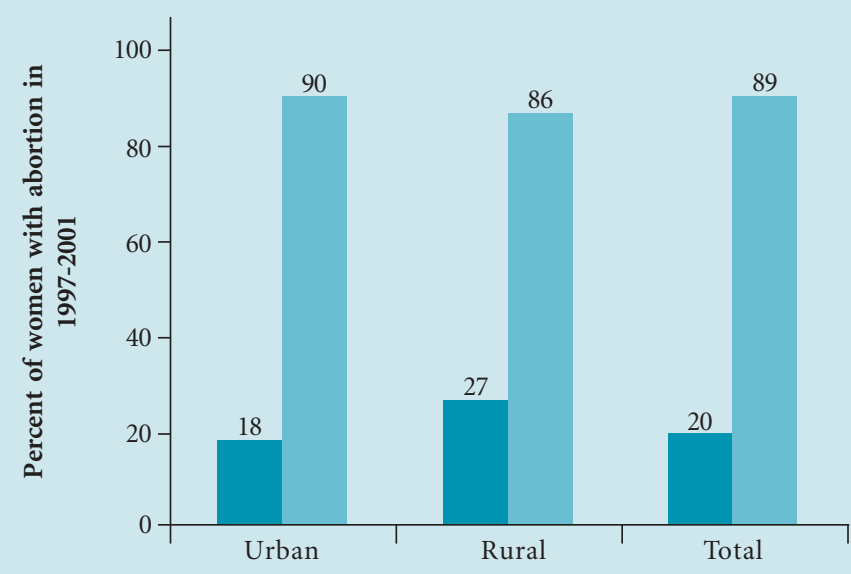

Used home remedies and/or informal-sector services

Used formal-sector services 


\section{Figure 4.5}

Type of formal abortion provider
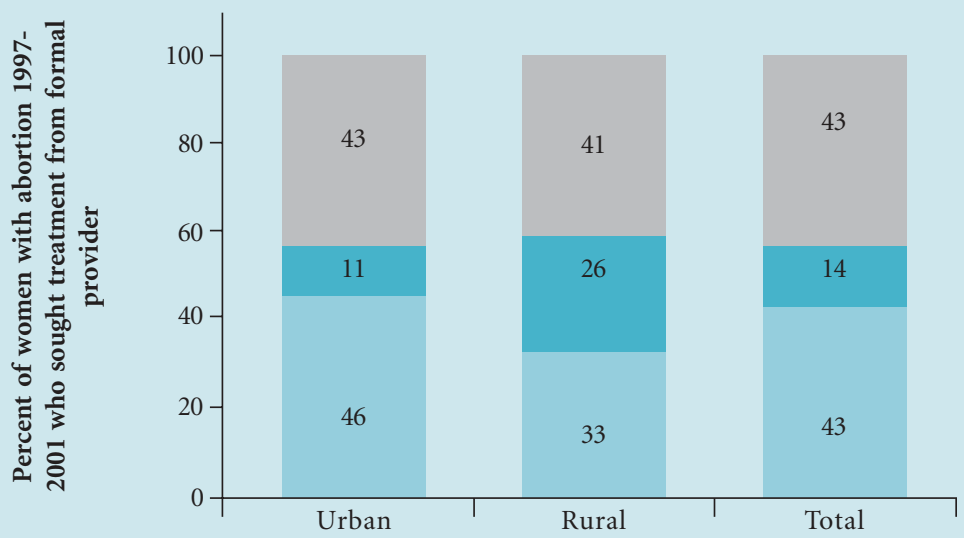

District hospital doctor

Community health centre/primary health centre doctor

Private doctor

Table 4.2

Reasons for choosing and source of information about provider (\%)

\begin{tabular}{|l|c|c|c|}
\hline & Urban & Rural & Total \\
\hline Reasons for choosing provider ${ }^{\text {a }}$ & & & \\
\hline Good/popular doctor & 42.1 & 35.7 & 40.0 \\
\hline Family doctor & 37.0 & 26.2 & 34.5 \\
\hline Female doctor & 5.1 & 4.8 & 5.0 \\
\hline Government doctor & 5.1 & 4.8 & 5.0 \\
\hline Husband decided & 8.7 & 23.8 & 12.2 \\
\hline Auxiliary nurse midwife decided & 2.2 & 2.8 \\
\hline Proximity & 10.1 & 4.8 & 8.9 \\
\hline Immediate service & 2.2 & 4.8 & 2.2 \\
\hline Source of information about provider ${ }^{\text {a }}$ & & 2.4 & 46.1 \\
\hline Husband & 47.2 & & 40.0 \\
\hline Family member & 38.4 & 42.7 & 2.8 \\
\hline Friend & 2.9 & 45.3 & 2.2 \\
\hline Health worker & 1.4 & 2.4 & 1.1 \\
\hline Signboard & 0.7 & 4.8 & 7.8 \\
\hline Other & 9.4 & 2.4 & $\mathbf{1 8 0}$ \\
\hline Sought abortion from formal provider (n) & $\mathbf{1 3 8}$ & 2.4 & $\mathbf{4 2}$ \\
\hline (n) & & & \\
\hline
\end{tabular}

${ }^{a}$ May total to more than 100 percent because of multiple responses. 
husbands determined which provider to approach. In the case of ten percent of urban women, who undoubtedly had more options than rural women when seeking services in the formal sector, the proximity of the provider from their home played a role in their selection of an abortion provider. For most women, husbands (46 percent) and other family members ( 40 percent) were the primary source of information about a given provider.

While 80 percent of urban women obtained abortions from providers operating in their own city or town, only five percent of rural women sought services locally in their village (Figure 4.6). The bulk (81 percent) of rural women reporting abortions in the five years preceding the survey travelled to a nearby city or town to terminate their pregnancies. Poor access to abortion services among rural women is also apparent if we examine the time taken to reach the last provider (Figure 4.7). Eighty-one percent of urban women travelled 30 minutes or less to reach their provider compared to 45 percent of rural women. Nearly one-quarter (24 percent) of rural women took more than one hour to reach their abortion providers.

Women who sought services from atleast one formal-sector provider were asked about the cost of the services they received (Table 4.3). All women, including those who sought services in the public sector, incurred atleast some out-of-pocket costs. Nineteen percent of women reported a relatively modest sum of 100 Indian Rupees or less.

One-third (33 percent) of women, however, paid between 100 and 500 Indian Rupees for their abortions, and, even more noteworthy, another 34 percent spent in excess of 500 Indian Rupees to

\section{Figure 4.6}

Location of abortion provider consulted

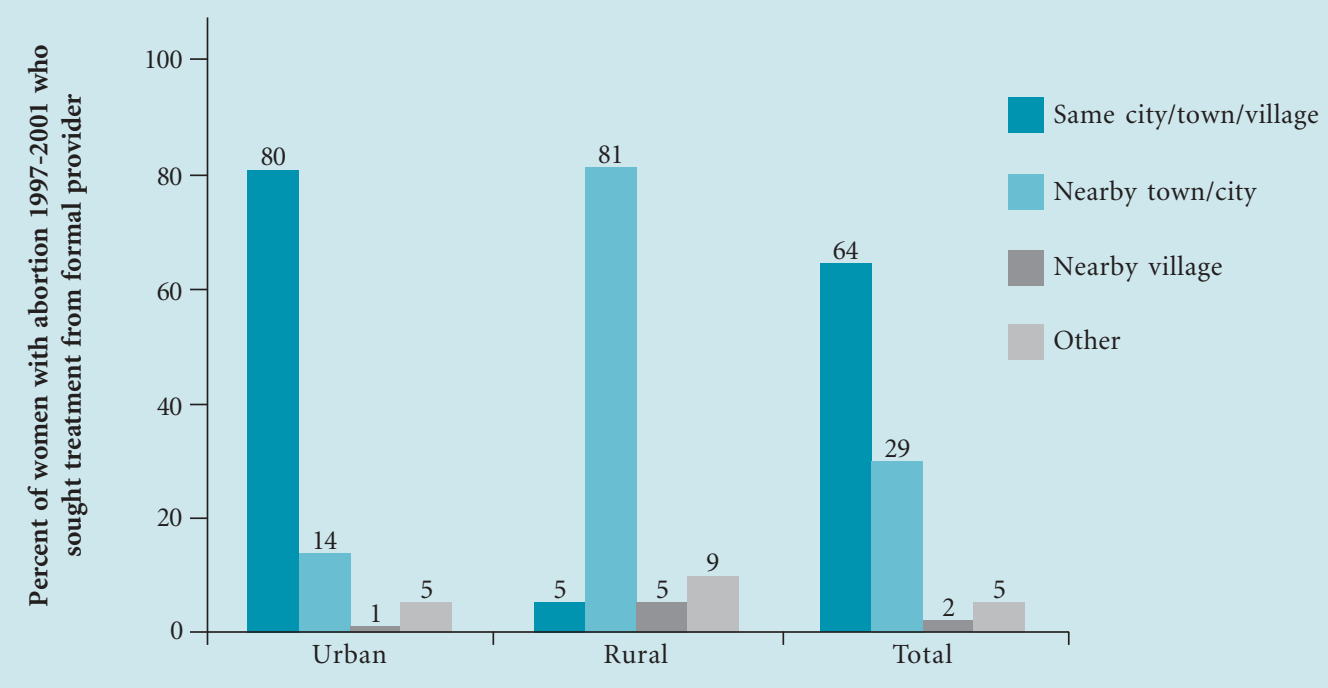


Figure 4.7

Time taken to reach abortion provider

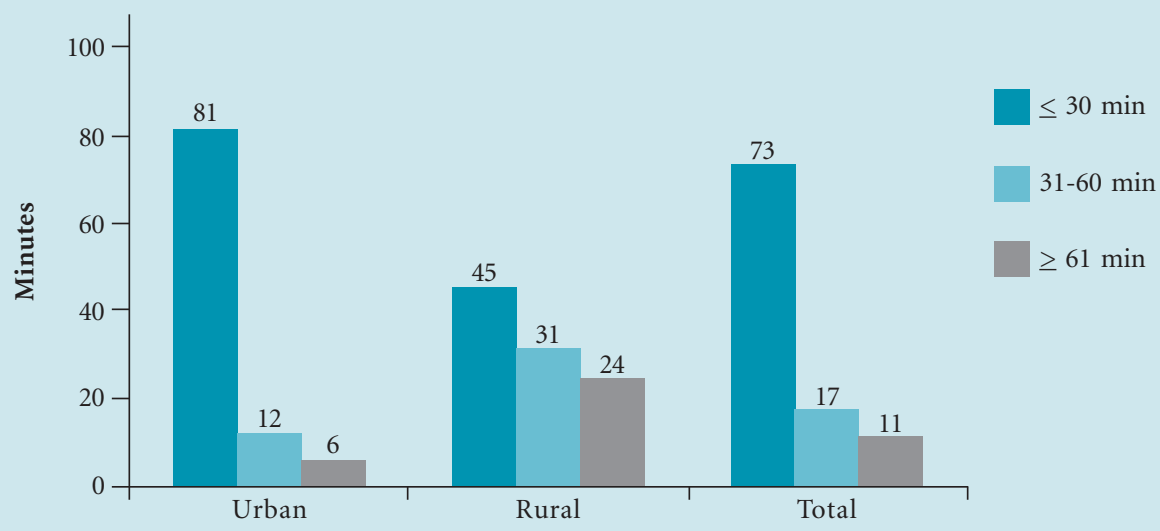

\section{Table 4.3}

Cost, family planning counselling and spousal consent (\%)

\begin{tabular}{|l|c|c|c|}
\hline & Urban & Rural & Total \\
\hline Amount paid (Indian Rupees) & & & \\
\hline$\leq 100$ & 18.9 & 19.1 & 18.8 \\
\hline $101-300$ & 14.4 & 9.5 & 13.4 \\
\hline $301-500$ & 19.6 & 21.4 & 20.0 \\
\hline $501-750$ & 10.1 & 7.1 & 9.4 \\
\hline 751 & 21.1 & 35.8 & 24.5 \\
\hline Do not know & 15.9 & 7.1 & 13.9 \\
\hline Mean amount paid (Indian Rupees) & 787 & 852 & 803 \\
\hline Provider discussed how to avoid future pregnancies & 47.1 & 16.7 & 40.0 \\
\hline Husband's consent taken by provider & 79.7 & 76.2 & 78.9 \\
\hline Sought abortion from formal provider $(\mathbf{n})$ & $\mathbf{1 3 8}$ & $\mathbf{4 2}$ & $\mathbf{1 8 0}$ \\
\hline
\end{tabular}

terminate their pregnancies.

Only 40 percent of women reported that their abortion provider had discussed how to avoid future pregnancies, with far fewer rural (17 percent) than urban women (47 percent) receiving such counselling (Table 4.3). Although not mandated by law, 79 percent of the women reported that the provider had taken their husband's consent (Table 4.3).

\section{Satisfaction with provider}

While the majority (76 percent) of women were very satisfied with their abortion provider, rural respondents were far more tepid in their assessments. Indeed, 
12 percent of rural women were dissatisfied with their abortion provider (Figure 4.8). Despite this, 92 percent of both urban women and rural would recommend the provider to others (data not shown).

\section{Post-abortion experiences}

\section{Post-abortion morbidity}

As Table 4.4 shows, 26 percent of women who reported abortions in the five years preceding the survey experienced post-abortion morbidity, with slightly more rural ( 29 percent) than urban ( 25 percent) women experiencing such morbidity. The most commonly reported problem resulting from abortion was a backache (15 percent). Signs of sepsis—-foul-smelling discharge combined with a high-grade fever-while reported by only a few women ( 5 percent) with abortions, were more common among rural (8 percent) than urban (5 percent) women.
While most women did not experience problems after their abortions, the majority of those who did ( 83 percent) were required to remain in bed for atleast one day and were unable to carry out routine household chores (Table 4.4). Nearly half ( 45 percent) of women who experienced problems after their abortions sought formal medical treatment. Rural women (64 percent) were far more likely to seek treatment for their abortion complications than urban women (39 percent), suggesting that they experienced more severe morbidity. Thirteen percent of women with post-abortion morbidity were reportedly hospitalised.

\section{Post-abortion family planning}

Nearly 40 percent of women who reported an abortion in the five years preceding the survey did not adopt a family planning method following their abortions (Table 4.5). Rural women were particularly

Figure 4.8

Satisfaction with abortion provider

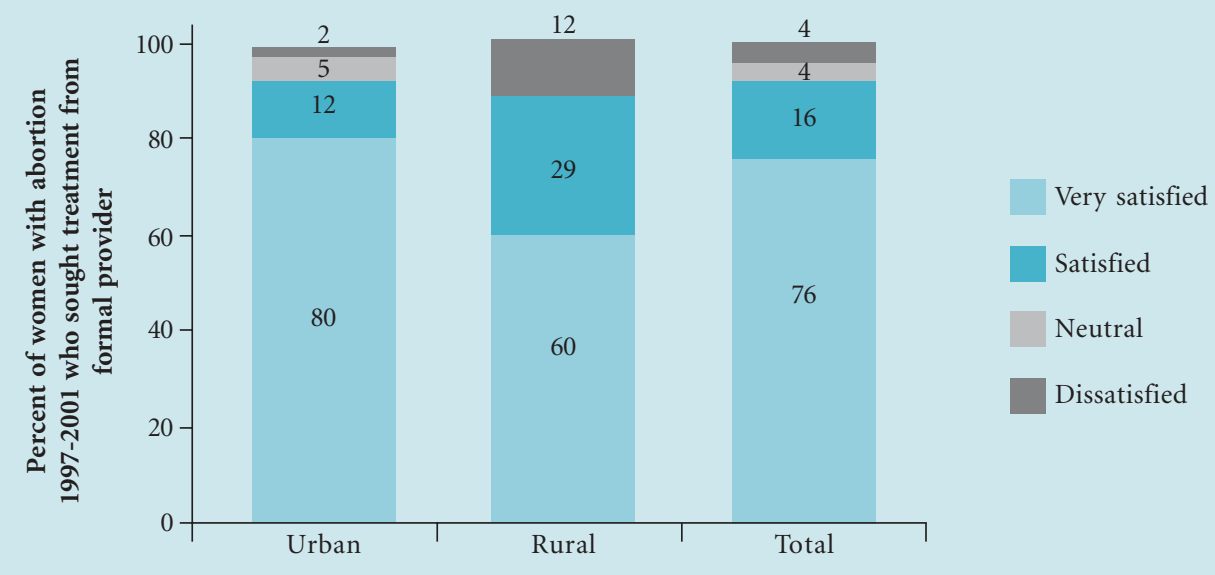


Table 4.4

Experiences with post-abortion morbidity(\%)

\begin{tabular}{|l|c|c|c|}
\hline & Urban & Rural & Total \\
\hline Post-abortion morbidity & & \\
\hline None & & 73.9 \\
Backache & 74.7 & 71.4 & 15.1 \\
\hline Abdominal pain & 16.4 & 14.4 & 4.4 \\
\hline Fatigue and weakness & 5.2 & 2.3 & 5.5 \\
\hline Foul-smelling discharge and high-grade fever & 5.4 & 5.9 & 5.4 \\
\hline Persistent bleeding for $\geq 4$ weeks & 5.1 & 8.3 & 3.4 \\
\hline Had induced abortion 1997-2001 (n) & 3.3 & 4.2 & $\mathbf{2 0 3}$ \\
\hline Bed rest for atleast one day & $\mathbf{1 5 4}$ & 49 & 83.0 \\
\hline Affected ability to do regular household work & 84.6 & 78.6 & 45.3 \\
\hline Sought treatment for morbidity & 84.6 & 78.6 & 13.2 \\
\hline Hospitalised for morbidity & 38.5 & 64.3 & $\mathbf{5 3}$ \\
\hline Experienced post-abortion morbidity (n) & 12.8 & 14.3 & $\mathbf{1 4}$ \\
\hline
\end{tabular}

${ }^{a}$ May total to more than 100 percent because of multiple responses.

Table 4.5

Use of post-abortion family planning (\%)

\begin{tabular}{|l|c|c|c|}
\hline & Urban & Rural & Total \\
\hline Method used & & & \\
\hline None & 32.5 & 55.1 & 37.9 \\
\hline Sterilisation & 20.0 & 18.4 & 19.9 \\
Oral contraceptive pills & 16.1 & 12.2 & 15.2 \\
\hline Intrauterine device & 9.5 & - & 7.3 \\
\hline Condoms & 18.8 & 10.2 & 14.9 \\
\hline Safe period/withdrawal & 3.1 & 4.1 & 5.5 \\
\hline Had induced abortion 1997-2001 (n) & 154 & 49 & 203 \\
\hline Duration of use (months) & & & 16.7 \\
\hline 1 & 15.4 & 22.7 & 19.8 \\
\hline $2-6$ & 18.3 & 27.3 & 11.9 \\
\hline $7-12$ & 12.5 & 9.1 & 51.6 \\
\hline 13 & 53.8 & 40.9 & $\mathbf{1 2 6}$ \\
\hline Adopted post-abortion family planning (n) & $\mathbf{1 0 4}$ & $\mathbf{2 2}$ & \\
\hline
\end{tabular}


unlikely to use family planning after their abortions (urban: 33 percent; rural: 55 percent).

Nearly one-fifth of women were sterilised following their abortions (18 percent). Similar proportions of women began using oral contraceptive pills ( 15 percent) or condoms (15 percent) following their abortions. In a fair number of cases (17 percent), however, post-abortion family planning use was short-lived, lasting for one month or less (Table 4.5).

Data not shown suggest that a substantial number of the women who did not adopt a family planning method after their abortions had experienced opposition to use from their husbands, were apprehensive of possible side effects or simply were unaware of any methods. 


\section{Knowledge of and Attitudes Towards Abortion}

This chapter presents data on male and female respondents' knowledge of the legality of abortion in India and their opinions regarding abortion law, risks and services. Information on respondents' familiarity with sex determination and sex-selective abortion is also included in this chapter.

\section{Abortion legality}

\section{Knowledge of the legality of abortion}

Knowledge of the legality of abortion in India was extremely poor among both men and women (Figure 5.1). Only 16 percent of male and 17 percent of female respondents knew correctly that abortion is legal. Rural women were the least likely to be aware of the legality of abortion in India, with only 13 percent of them reporting abortion to be legal. The majority of women ( 55 percent) and men ( 78 percent) believed incorrectly that it is illegal.

The 95 male and 538 female respondents who were aware that abortion is legal in India were further queried about the specific conditions under which abortion can be performed legally (Table 5.1). Most of these respondents knew that abortion was legal in cases of foetal malformation (men: 85 percent; women: 94 percent), rape (men: 71 percent; women: 98 percent), risk to the mother's health (men: 86 percent; women: 88 percent) or contraceptive failure (men: 72 percent; women: 81 percent). However, misinformation regarding other aspects of the MTP Act was pervasive. Only 54 percent of male

Figure 5.1

Awareness of the legality of abortion

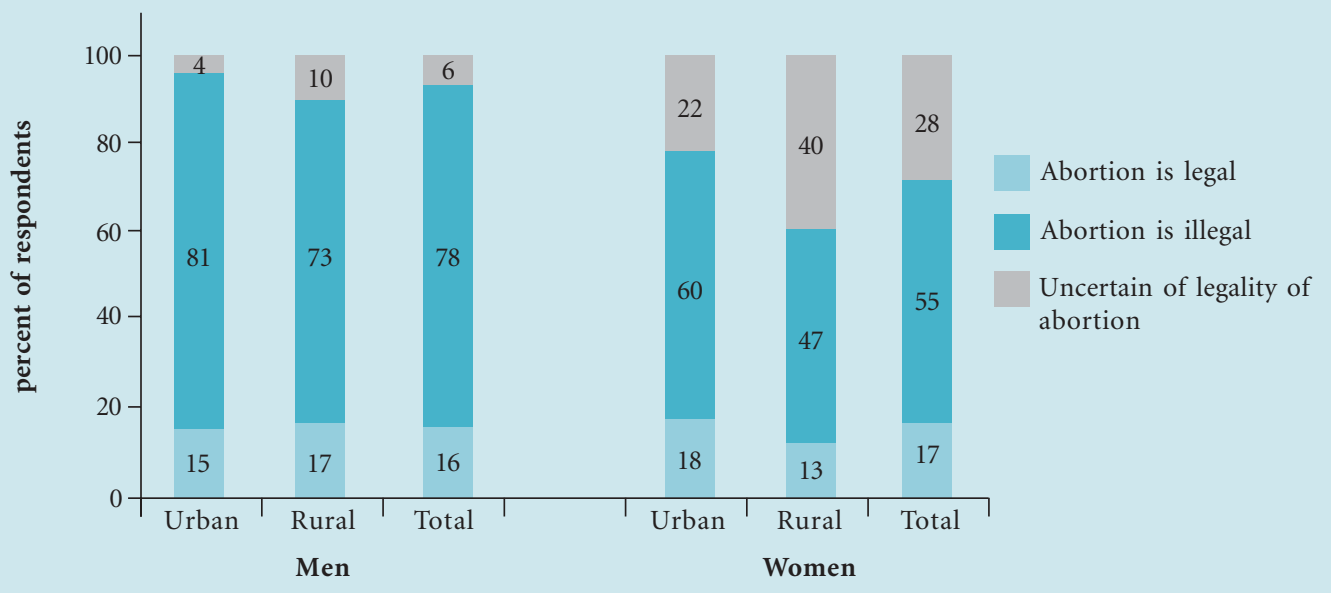


Table 5.1

Familiarity with details of MTP Act (\%)

\begin{tabular}{|c|c|c|c|c|c|c|}
\hline & \multicolumn{3}{|c|}{ Men } & \multicolumn{3}{|c|}{ Women } \\
\hline & Urban & Rural & Total & Urban & Rural & Total \\
\hline \multicolumn{7}{|l|}{ Aware of legal indications } \\
\hline Foetal malformation & 89.8 & 77.7 & 85.2 & 95.3 & 90.1 & 93.6 \\
\hline Rape & 67.7 & 75.0 & 70.5 & 97.5 & 98.2 & 97.7 \\
\hline Woman's health endangered by pregnancy & 86.4 & 86.1 & 86.3 & 91.2 & 80.8 & 87.9 \\
\hline Contraceptive failure & 71.1 & 72.2 & 71.5 & 82.7 & 76.7 & 80.8 \\
\hline Unmarried woman & 50.8 & 58.3 & 53.6 & 95.3 & 95.9 & 95.5 \\
\hline \multicolumn{7}{|l|}{ Aware of illegal indications } \\
\hline$>20$ weeks' gestation & 81.3 & 75.0 & 78.9 & 93.1 & 81.9 & 89.5 \\
\hline Aware that abortion is legal (n) & 59 & 36 & 95 & 366 & 172 & 538 \\
\hline
\end{tabular}

respondents knew that an unmarried woman can legally obtain an abortion. Equally noteworthy, 25 percent of rural men were unaware that abortion is illegal after 20 weeks' gestation.

While the MTP Act does not stipulate that a husband's consent must be obtained prior to abortion, 94 percent of all men interviewed and 98 percent of all women interviewed incorrectly believed that such consent is mandated by law (Figure 5.2).

\section{Attitudes towards abortion legality}

As indicated in Table 5.2, attitudes towards abortion were similar across both gender groups, with large proportions of men and women respondents endorsing abortion in a wide variety of circumstances. Indeed, an overwhelming majority of men and women approved of abortion if an unmarried woman becomes pregnant (men: 92 percent; women: 93 percent) or if the pregnancy results from rape (men: 93 percent; women; 92 percent). Acceptance of abortion was also high in the case of poor maternal health (men: 88 percent; women: 85 percent) and foetal malformation (men: 84 percent; women: 88 percent). Respondents were less supportive of abortion if a woman does not want the child (men: 76 percent; women: 83 percent), if the family cannot afford to have the child (men: 70 percent; women: 79 percent) or if the pregnancy results from contraceptive failure (men: 65 percent; women: 65 percent). Significantly more female (20 percent) than male respondents ( 8 percent), and more rural (men: 14 percent; women: 27 percent) than urban respondents (men: 4 percent; women: 16 percent) favoured abortion if the foetus is female. 


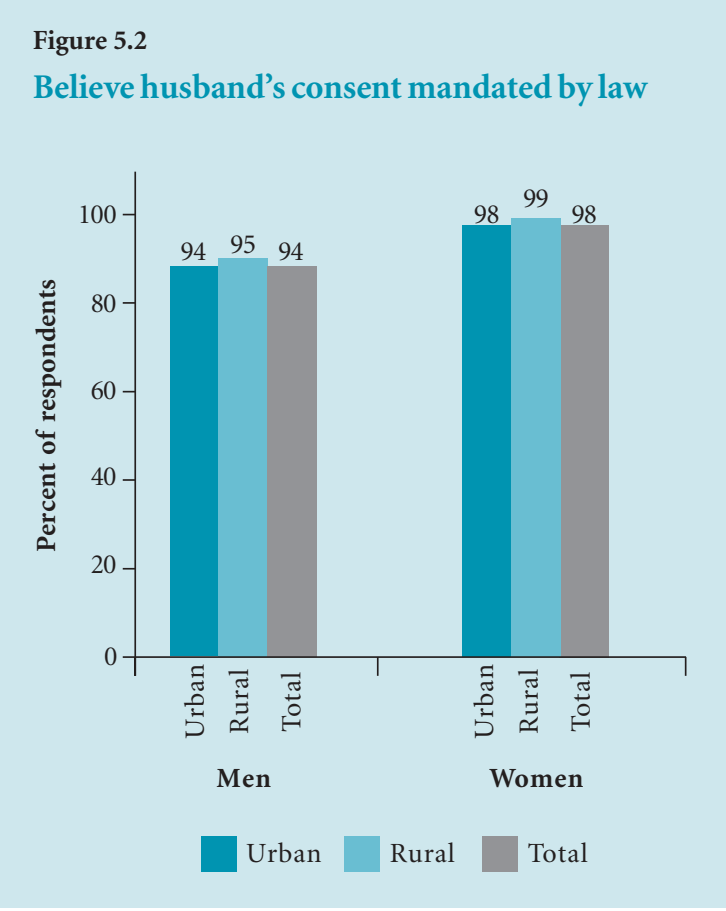

\section{Abortion risks and services}

\section{Risks associated with abortion}

Respondents were asked two questions to gauge their familiarity with the risks associated with abortion. The first question focused on the possibility of complications following abortion (Figure 5.3) and the second on the necessity of a trained provider for second-trimester abortions (Figure 5.4). Eighty-four percent of men and 82 percent of women agreed that abortion may be associated with complications such as infection and haemorrhage (Figure 5.3). A fair number of urban men (14 percent), however, explicitly disagreed with this statement.

\section{Seventy-five percent of men and 74 percent of} women agreed that trained providers should be consulted for abortions between 12 and 20 weeks'

Table 5.2

Approval of abortion by reason among men and women (\%)

\begin{tabular}{|l|c|c|c|c|c|c|c|}
\hline & \multicolumn{3}{|c|}{ Men } & \multicolumn{3}{c|}{ Women } \\
\cline { 2 - 9 } & Urban & Rural & Total & Urban & Rural & Total \\
\hline Foetal malformation & 86.0 & 81.4 & 84.4 & 90.6 & 82.8 & 87.5 \\
\hline Rape & 92.2 & 94.0 & 92.9 & 94.3 & 89.1 & 92.2 \\
\hline Woman's health endangered by pregnancy & 89.1 & 84.7 & 87.5 & 88.4 & 80.1 & 85.1 \\
Contraceptive failure & 61.2 & 70.7 & 64.6 & 68.2 & 58.8 & 64.5 \\
\hline Unmarried woman & 91.5 & 92.6 & 91.9 & 92.9 & 93.4 & 93.1 \\
\hline Woman does not want another child & 73.9 & 80.5 & 76.2 & 86.4 & 77.4 & 82.9 \\
\hline Financial concerns & 66.7 & 77.2 & 70.4 & 82.7 & 74.2 & 79.3 \\
\hline Female foetus & 4.4 & 13.5 & 7.6 & 15.8 & 27.0 & 20.2 \\
\hline >20 weeks' gestation & 2.3 & 7.0 & 4.0 & 4.0 & 6.0 & 4.8 \\
\hline Respondents (n) & 387 & 215 & $\mathbf{6 0 2}$ & $\mathbf{1 , 9 6 9}$ & $\mathbf{1 , 2 9 7}$ & $\mathbf{3 , 2 6 6}$ \\
\hline
\end{tabular}


gestation (Figure 5.4). Over one-quarter of urban men (28 percent) and a significant proportion of rural women (19 percent), however, disagreed with this assertion.

\section{Provider preferences}

In order to increase women's access to safe abortion and improve the quality of care of available services, it is important to understand the factors that may

\section{Figure 5.3}

Agreement with statement that abortion may be associated with infection and/or haemorrhage

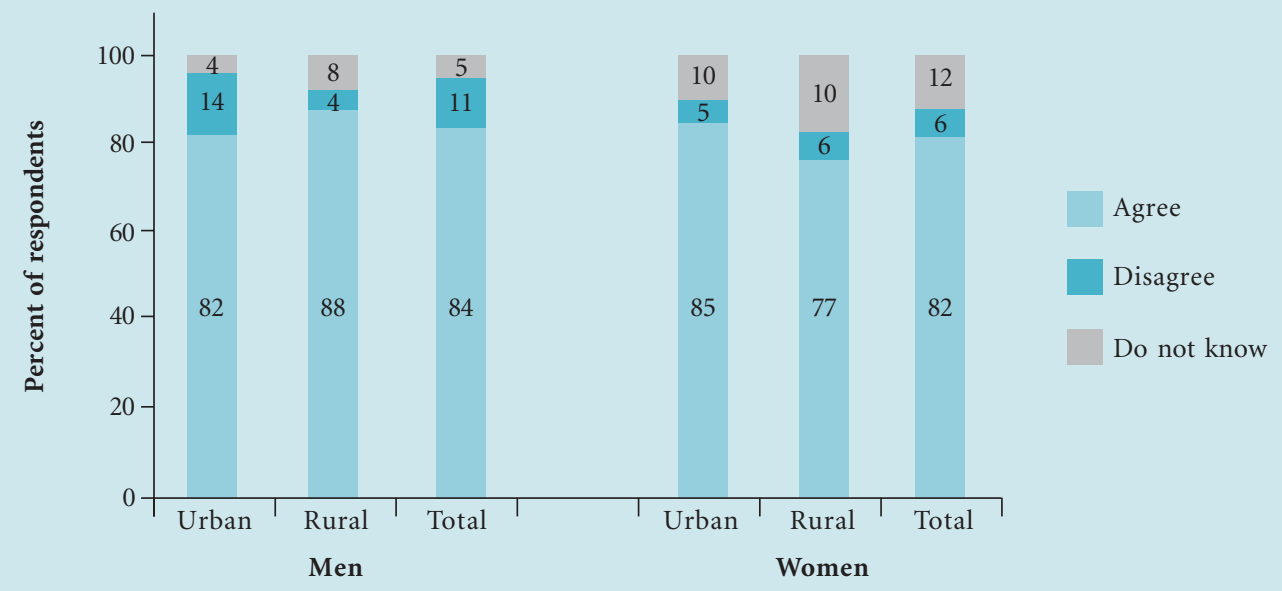

Figure 5.4

Agreement with statement that trained providers are required for second-trimester abortion

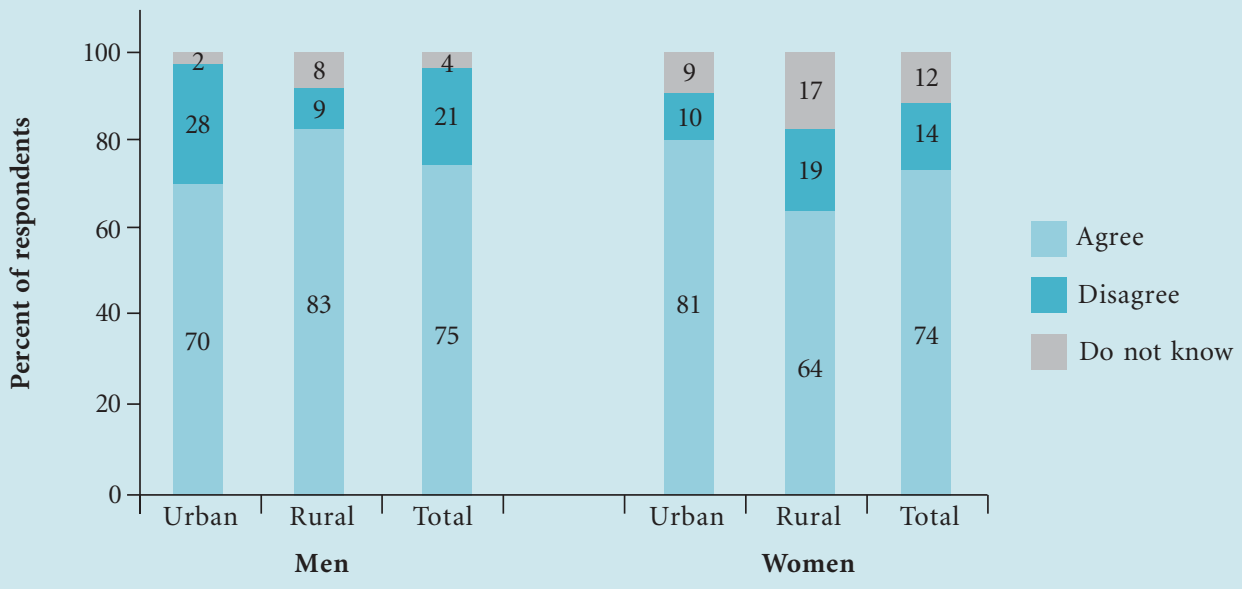


influence the selection of an abortion facility and provider. Respondents were read a list of facility and provider attributes and asked to indicate the importance they would give to each one when

choosing an abortion facility or provider (Table 5.3).

Approximately two-thirds to three-quarters of male

Table 5.3

Preferences for abortion facilities and providers (\%)

\begin{tabular}{|c|c|c|c|c|c|c|c|c|c|c|c|c|}
\hline & \multicolumn{4}{|c|}{ Urban } & \multicolumn{4}{|c|}{ Rural } & \multicolumn{4}{|c|}{ Total } \\
\hline & $\begin{array}{c}\text { Not } \\
\text { impor- } \\
\operatorname{tant}\end{array}$ & $\begin{array}{c}\text { Some } \\
\text { what } \\
\text { impor- } \\
\text { tant }\end{array}$ & $\begin{array}{c}\text { Impor- } \\
\tan t\end{array}$ & $\begin{array}{c}\text { Very } \\
\text { impor- } \\
\text { tant }\end{array}$ & $\begin{array}{c}\text { Not } \\
\text { impor- } \\
\text { tant }\end{array}$ & $\begin{array}{c}\text { Some } \\
\text { what } \\
\text { impor- } \\
\text { tant }\end{array}$ & $\begin{array}{c}\text { impor- } \\
\tan t\end{array}$ & $\begin{array}{c}\text { Very } \\
\text { impor- } \\
\text { tant }\end{array}$ & $\begin{array}{c}\text { Not } \\
\text { impor- } \\
\text { tant }\end{array}$ & $\begin{array}{c}\text { Some } \\
\text { what } \\
\text { impor- } \\
\text { tant }\end{array}$ & $\begin{array}{c}\text { Impor- } \\
\text { tant }\end{array}$ & $\begin{array}{c}\text { Very } \\
\text { impor- } \\
\text { tant }\end{array}$ \\
\hline \multicolumn{13}{|l|}{ Men } \\
\hline Female provider & 33.6 & 13.4 & 31.5 & 21.4 & 13.0 & 19.5 & 35.3 & 32.1 & 26.2 & 15.6 & 32.9 & 25.2 \\
\hline Cost & 13.2 & 15.5 & 46.3 & 25.1 & 13.0 & 11.6 & 53.0 & 22.3 & 13.1 & 14.1 & 48.7 & 24.1 \\
\hline Privacy & 12.9 & 4.1 & 40.1 & 42.9 & 9.8 & 8.4 & 38.6 & 43.3 & 11.8 & 5.6 & 39.5 & 43.0 \\
\hline Provider skill & 0.8 & 1.8 & 29.2 & 68.2 & 3.3 & 4.7 & 39.1 & 53.0 & 1.7 & 2.8 & 32.7 & 62.8 \\
\hline Well-equipped facility & 1.0 & 1.6 & 28.4 & 69.0 & 2.3 & 4.2 & 39.5 & 54.0 & 1.5 & 2.5 & 32.4 & 63.6 \\
\hline Legal provider & 2.1 & 1.3 & 22.7 & 73.9 & 2.3 & 6.0 & 36.3 & 55.3 & 2.2 & 3.0 & 27.6 & 67.3 \\
\hline Distance from home & 40.1 & 21.7 & 27.6 & 10.6 & 34.4 & 19.1 & 27.0 & 19.5 & 38.0 & 20.8 & 27.4 & 13.8 \\
\hline $\begin{array}{l}\text { Husband's consent } \\
\text { not required }\end{array}$ & 25.8 & 3.9 & 19.9 & 50.4 & 13.5 & 4.2 & 15.8 & 66.5 & 21.4 & 4.0 & 18.4 & 56.1 \\
\hline $\begin{array}{l}\text { Not forced to } \\
\text { accept contraception }\end{array}$ & 40.1 & 22.2 & 20.7 & 17.1 & 42.8 & 18.6 & 18.1 & 20.5 & 41.0 & 20.9 & 19.8 & 18.3 \\
\hline $\operatorname{Men}(\mathbf{n})$ & \multicolumn{4}{|c|}{387} & \multicolumn{4}{|c|}{215} & \multicolumn{4}{|c|}{602} \\
\hline \multicolumn{13}{|l|}{ Women } \\
\hline Female provider & 19.4 & 8.2 & 28.7 & 43.4 & 9.9 & 6.5 & 29.9 & 53.4 & 15.7 & 7.6 & 29.2 & 47.4 \\
\hline Cost & 12.3 & 15.4 & 47.6 & 24.4 & 9.2 & 11.8 & 36.3 & 42.5 & 11.1 & 14.0 & 43.2 & 31.6 \\
\hline Privacy & 17.3 & 11.3 & 33.0 & 38.3 & 17.6 & 11.9 & 24.9 & 45.4 & 17.4 & 11.5 & 29.8 & 41.1 \\
\hline Provider skill & 1.3 & 0.8 & 28.7 & 69.0 & 2.7 & 3.4 & 30.8 & 62.9 & 1.9 & 1.8 & 29.6 & 66.6 \\
\hline Well-equipped facility & 1.0 & 2.4 & 17.0 & 79.4 & 2.3 & 6.8 & 19.2 & 71.5 & 1.5 & 4.2 & 17.9 & 76.3 \\
\hline Legal provider & 2.2 & 1.2 & 24.0 & 72.6 & 3.1 & 4.5 & 22.9 & 69.5 & 2.6 & 2.5 & 23.6 & 71.3 \\
\hline Distance from home & 42.9 & 19.4 & 22.7 & 15.1 & 43.4 & 18.0 & 19.1 & 19.5 & 43.1 & 18.8 & 21.2 & 16.8 \\
\hline $\begin{array}{l}\text { Husband's consent } \\
\text { not required }\end{array}$ & 29.5 & 4.8 & 17.3 & 48.5 & 11.7 & 5.1 & 20.5 & 62.7 & 22.4 & 4.9 & 18.6 & 54.1 \\
\hline $\begin{array}{l}\text { Not forced to } \\
\text { accept contraception }\end{array}$ & 50.1 & 14.7 & 18.6 & 16.7 & 49.7 & 14.9 & 18.5 & 16.9 & 49.9 & 14.8 & 18.6 & 16.7 \\
\hline Women (n) & \multicolumn{4}{|c|}{1,969} & \multicolumn{4}{|c|}{1,297} & \multicolumn{4}{|c|}{3,266} \\
\hline
\end{tabular}


and female respondents reported that a provider's skill, an equipped facility and a legal provider would be very important in their selection of an abortion provider. Urban men (provider skill: 68 percent; equipped facility: 69 percent; legal provider: 74 percent) and women (provider skill: 69 percent; equipped facility: 79 percent; legal provider: 73 percent) were more likely to rate these factors as very important than rural men (provider skill: 53 percent; equipped facility: 54 percent; legal provider: 55 percent) and women (provider skill: 63 percent; equipped facility: 72 percent; legal provider: 70 percent). Many respondents, whether male (56 percent) or female (54 percent), or from urban (men: 50 percent; women; 49 percent) or rural areas (men: 67 percent; women: 63 percent), preferred providers who do not require a husband's consent. When compared to all other respondents, rural women placed the greatest value on a female provider, the cost of the procedure and the privacy of the service, with 53, 43 and 45 percent of them, respectively, rating those facility or provider characteristics to be very important. Approximately one-third to one-half of all respondents reported that requirements regarding the adoption of contraception post abortion (men: 41 percent; women: 50 percent) and the distance of the provider from their home (men: 38 percent; women: 43 percent) would not play an important role in their selection of an abortion provider.

\section{Sex determination and sex-selective abortion}

As indicated in Figure 5.5, 80 percent of men and 75 percent of women knew that foetal sex can be determined. Knowledge of sex determination was significantly higher among urban respondents (men: 88 percent; women 88 percent) than rural respondents (men: 66 percent; women: 55 percent).

Respondents familiar with sex determination were further queried as to whether they knew of a facility for sex determination or knew someone who had undergone a sex-selective abortion, and were asked to indicate how common they believe such

\section{Figure 5.5}

Knowledge of sex determination

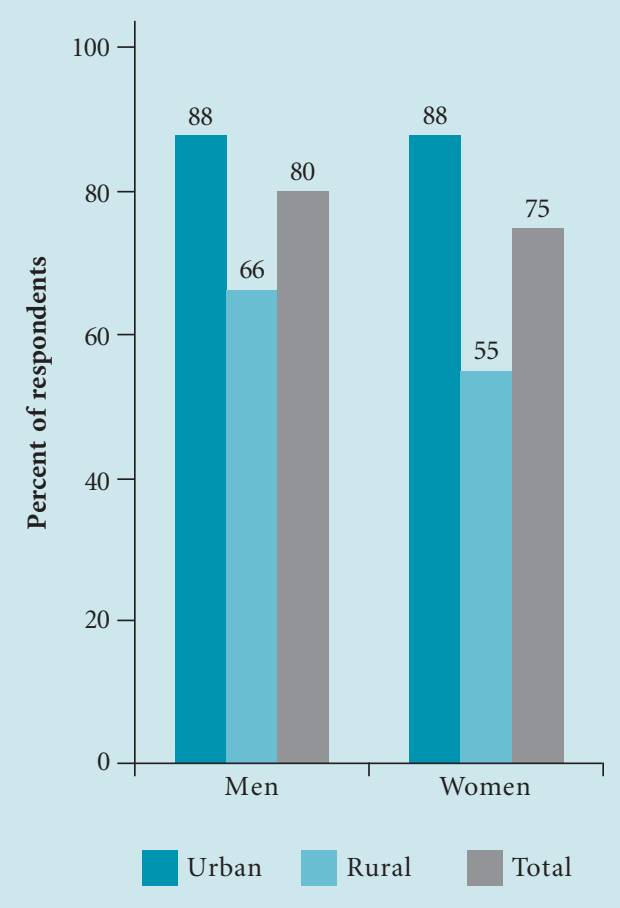


abortions are in their community (Table 5.4).

Among the respondents aware of sex determination, 98 percent of men and women knew of a facility where women could obtain the service, with very little difference by urban-rural residence. The majority of respondents familiar with sex determination (76 percent) reportedly knew someone who had undergone a sex-selective abortion.
Urban respondents (men: 85 percent; women: 79 percent) were more likely to report that they knew someone who had had a sex-selective abortion than rural respondents (men: 55 percent; women: 69 percent). Forty-five percent of men and 70 percent of women who knew someone who had had a sex-selective abortion reported that this practice was very common in their community.

Table 5.4

Knowledge of sex determination and sex-selective abortion (\%)

\begin{tabular}{|l|c|c|c|c|c|c|c|}
\hline & \multicolumn{3}{|c|}{ Men } & \multicolumn{3}{c|}{ Women } \\
\cline { 2 - 7 } & Urban & Rural & Total & Urban & Rural & Total \\
\hline Knew of a facility for sex determination & 98.5 & 97.2 & 98.1 & 98.0 & 96.6 & 97.6 \\
$\begin{array}{l}\text { Knew someone who had aborted a } \\
\text { female foetus }\end{array}$ & 84.7 & 55.3 & 76.1 & 79.1 & 68.5 & 76.0 \\
\hline $\begin{array}{l}\text { Aware of sex determination (n) } \\
\text { Frequency of sex-selective abortion }\end{array}$ & $\mathbf{3 4 0}$ & $\mathbf{1 4 1}$ & $\mathbf{4 8 1}$ & $\mathbf{1 , 7 3 7}$ & $\mathbf{7 1 4}$ & $\mathbf{2 , 4 5 1}$ \\
\hline $\begin{array}{l}\text { Very common } \\
\text { Somewhat common }\end{array}$ & 47.9 & 35.9 & 45.4 & 70.7 & 66.2 & 69.5 \\
\hline $\begin{array}{l}\text { Not common } \\
\text { Cannot say }\end{array}$ & 30.9 & 46.2 & 34.2 & 27.4 & 30.7 & 28.2 \\
\hline $\begin{array}{l}\text { Knew someone who had a } \\
\text { sex-selective abortion (n) }\end{array}$ & 20.8 & 17.9 & 20.2 & 1.7 & 3.1 & 2.0 \\
\hline
\end{tabular}




\section{Summary of Findings and Conclusion}

We conducted a community-based study of unwanted pregnancy and induced abortion in six purposively selected districts of Rajasthan. While the 3,266 female and 606 male respondents were sampled largely from urban areas-district headquarters and medium-sized towns-we also drew respondents from villages and smaller towns surrounding those urban localities.

Our study offers important insights into the levels of unwanted pregnancy and induced abortion in the sampled areas in Rajasthan, as well as the experiences of women undergoing abortions there. The study also provides detailed information about men and women's knowledge and opinions of the legality of abortion in India, as well as of abortion risks and services, which is likely to be of significant interest to policy-makers and programme managers.

\section{Unwanted pregnancy}

- One-tenth of all pregnancies occurring in the five years preceding the survey were unwantedgenerally either not wanted at all or wanted later.

Only a few (4 percent) pregnancies were considered unwanted because a child of a different sex was desired. As 70 percent of induced abortions resulted from unwanted pregnancies, the importance of reducing unwanted pregnancies through temporary, in addition to permanent, methods of contraception is clear if women are to meet their reproductive intentions.

\section{Levels of abortion}

- Abortion rates are considerable in the sampled areas in Rajasthan, with 13 percent of all women interviewed experiencing atleast one abortion. Women of higher socio-economic status were even more likely to ever have had at least one abortion suggesting that the demand for fertility regulation and /or access to pregnancy termination services is greater among such women.

- An analysis of abortion ratios over time indicates that abortion levels have increased substantially in the past decade, particularly in urban areas.

While the increase in the number of induced abortions relative to live births could be linked to a number of factors, including improvements in the familiarity with and/or access to abortion services, stronger desires to limit family size are likely playing a role as well.

\section{Reasons for abortions}

- The vast majority of women had abortions because they (59 percent) or their spouse (18 percent) wanted to limit their family size or space their childbearing (22 percent), further highlighting an unmet need for both permanent and temporary methods of family planning. Far fewer women, however, explicitly mentioned a legal indication for abortion, including problems in the woman's health (20 percent), contraceptive failure (2 percent) or foetal malformation ( 2 percent). Sex preferences appear to drive only a very small proportion of women ( 2 percent) to terminate their pregnancies.

\section{Spousal and family involvement}

- Women's husbands and other family members play a significant role in the decision to have an abortion and the selection of an abortion provider. Regardless of whether women resided in an urban 
or rural area, husbands often participated in the decision to seek an abortion (55 percent) or were solely responsible for the decision (25 percent). Significant proportions of women with recent abortions also reported that they learned of their abortion provider from their husbands

(46 percent) and/or other family members (40 percent). Further research is clearly needed to illuminate the dynamics of this decision-making process and the nature of spousal communication about abortion as it is likely that both partners may find their choices shaped by family dynamics or social conventions.

- Current medical practice is likely to reinforce men's role in the abortion process. Indeed, while the MTP Act does not mandate a husband's consent, four-fifths ( 80 percent) of women with induced abortions in the five years preceding the survey indicated that the provider required such consent in order to perform the procedure. While providers may demand spousal consent, however, men and women clearly prefer otherwise-over half of all men and women in our study indicated that the absence of spousal consent requirements would be very important to them when selecting an abortion provider. Particularly among women who obtain an abortion without their spouse's knowledge (28 percent in our study), spousal consent requirements may deter them from seeking services in the formal sector.

\section{Abortion treatments and providers}

- For many women, obtaining an abortion is a process that may well entail the consumption of home remedies, as well as the use of informal and formal services. Indeed, 20 percent of women with abortions in the five years preceding the study reportedly used a home remedy or obtained services from an informal provider in an attempt to terminate their pregnancies. As in some cases these actions proved unsuccessful, the majority (89 percent) of women eventually sought services from the formal sector. Even when seeking services in the formal sector, though, some women had to visit more than one provider to terminate their pregnancies. In addition to the time and financial outputs associated with each attempt at abortion, this process may lead to delays in seeking care that may in turn increase the risk of complications.

- Private-sector doctors emerged as important providers of abortion in both urban and rural areas, used by 43 percent of women seeking services in the formal sector. This finding underscores the need to better understand the quality of services among private providers and to truly engage such providers in policy and programme dialogues regarding abortion.

- Access to services among rural and poor women is abysmal. Despite a government commitment to increase access to abortion services in rural areas, only five percent of rural women with recent abortions availed of services locally, in their villages. One-quarter (24 percent) travelled over one hour to reach an abortion provider. Additionally, although provisions for free MTP services exist in the public sector, all women incurred at least some out-ofpocket costs when obtaining abortions. In many cases ( 34 percent), those costs were substantial, well over 500 Indian Rupees. 


\section{Post-abortion experiences}

- Post-abortion contraception counselling and adoption was low, representing a significant lost opportunity. While most women obtaining abortions desired to limit or space their childbearing, the majority (60 percent) of them did not receive any information or counselling regarding family planning, particularly in rural areas where only 17 percent indicated that providers discussed family planning with them. Similarly, while 60 percent of women adopted a method of family planning after their abortions, use was often short-lived, limited to less than one month in 17 percent of cases. These findings highlight the need for appropriate contraceptive counselling that enables women to select methods that they are likely to find acceptable.

- Levels of post-abortion morbidity were relatively modest in our study and surprisingly similar across the urban and rural samples. Nearly all women who experienced morbidity, however, indicated that the problems they encountered affected their daily life-leaving them bedridden for atleast one day ( 83 percent) or unable to complete routine household chores (83 percent). Nearly half (45 percent) of all women and approximately two-thirds (64 percent) of rural women with post-abortion complications sought formal treatment for them and a fair number (13 percent) were hospitalised, suggesting that when complications do occur they are likely to be severe, particularly in rural areas.

\section{Knowledge of the legality of abortion}

- Knowledge of the legality of abortion was extremely poor. Only 16 percent of men and 17 percent of women knew that abortion is legal in India. Rural women were particularly unlikely to know that abortion is legal in India.

When combined with inadequate access to services in rural areas, such poor knowledge of the legal right to abortion is likely to contribute to continued reliance on informal providers and uncertified formal providers.

\section{Sex-selective abortion}

- Despite the low number of reported sex-selective abortions, our study suggests that sex determination technology is widely available and the practice of sex-selective abortion very well known among men and women. Indeed, 80 percent of men and 75 percent of women knew that foetal sex could be determined.

The vast majority (76 percent) of these respondents also knew someone who had undergone a sex-selective abortion.

\section{Conclusion}

The key message that emerges from this study is that more than 30 years following the legalisation of abortion in India, the legal right to abortion is not a reality for the majority of women in our sample. The ineffective implementation of the law and the poor quality of care in existing abortion services are evident in the distances women travel to reach services, the charges they pay to end their pregnancies, the 
widespread practice of obtaining husbands' consent for abortion, the lack of any and/or effective counselling regarding post-abortion family planning, and the continued low levels of familiarity with the legality of abortion. The study also vividly highlights that women have strong desires to meet their reproductive intentions and that existing methods of family planning and abortion services are failing them.

Policy action is imperative if access to abortion is to improve. Public information campaigns to educate women, their spouses and other family members about the legal right to abortion must be implemented. Similarly, public and private providers must be better informed of the precise provisions in the MTP Act so they can implement it more effectively.
Most importantly, the MTP Act itself should be revisited. Recent dialogue between policy-makers, programme managers, women's health activists and researchers has resulted in several important amendments to the MTP Act. Indeed, the decentralisation of facility certification to the district level is an important step in increasing access to legal abortion services. Similarly, the provision of mifepristone-misoprostol by certified providers at uncertified facilities which have an established link to certified facilities for back-up services may increase the number of legal abortion providers. Further revisions, however, must be made if the MTP Act is to ensure women across India — whether rich or poor, or urban or rural—meaningful access to legal, safe and effective abortion services. 


\section{References}

Barge S, Bracken H, Elul B et al. 2004. Formal and Informal Abortion Services in Rajasthan, India: Results of a Situation Analysis. New Delhi, India: Population Council.

Barua A. 2002. Availability and accessibility of abortion care: Provider perspectives. Paper presented at Population Council Workshop entitled “Abortion in India: How Can Research Help Us Move Forward?” Goa, India.

Census of India.2002.2001 Census Results. http://www.censusindia.net/results/2001census_data_index.html. Accessed on August 18, 2004.

Chhabra R and Nuna SC. 1994. Abortion in India: An Overview. New Delhi, India: Veerendra Printers.

Elul B, Bracken H, Verma S et al. 2004. Unwanted Pregnancy and Induced Abortion in Rajasthan, India: A Qualitative Exploration. New Delhi, India: Population Council.

Ganatra BR. 2000. Induced abortions: Programmatic and policy implications of data emerging from an ongoing study in rural Maharashtra, India, in Sexual and Reproductive Health: Recent Advances, Future Directions, ed. C Puri and P Van Look. New Delhi, India: New Age International.

Ganatra BR, Coyaji KJ and Rao V. 1998. Too far, too little, too late: A community-based case-control study of maternal mortality in rural west Maharashtra. Bulletin of the World Health Organization 76(6): 591-98.

Government of India. 1971. The Medical Termination of Pregnancy Act. Act No. 34.

Gupte M, Bandewar S and Pisal H. 1997. Abortion needs of women in India: A case study of rural Maharashtra. Reproductive Health Matters 9: 77-86.

Gupta J. 1993. People like you never get it: An Indian family planning clinic. Reproductive Health Matters 1:39-43.

Huntington D, Mensch B and Toubia N. 1993. A new approach to eliciting information about induced abortion. Studies in Family Planning 24(2): 120-24.

Huntington D, Mensch B and Miller VC. 1996. Survey questions for the measurement of induced abortion. Studies in Family Planning 27(3): 155-61.

Indian Council of Medical Research (ICMR). 1989. Illegal Abortion in Rural Areas: A Task Force Study. New Delhi, India: Indian Council of Medical Research. 
International Institute for Population Sciences (IIPS) and ORC Macro. 2000. National Family Health Survey (NFHS-2), 1998-99: India. Mumbai, India: IIPS.

Johnston HB, Ved R, Lyall N et al. 2001. Post-abortion Complications and their Management: A Community Assessment Conducted in Rural Uttar Pradesh, India. Prime Technical Report \#23. Chapel Hill, USA: Intrah, Prime II Project.

Johnston HB. 2002. Abortion Practice in India: A Review of the Literature. Mumbai, India: Centre for Enquiry into Health and Allied Themes (CEHAT) and Research Centre for Anusandhan Trust.

Khan ME, Barge S, Kumar N et al. 1999. Abortion in India: Current situation and future challenges, in Implementing a Reproductive Health Agenda in India: The Beginning, ed. S Pachauri. New Delhi, India: Population Council.

Malhotra A, Nyblade L, Parasuraman S et al. 2003. Realizing Reproductive Choice and Rights: Abortion and Contraception in India. New Delhi, India: International Center for Research on Women.

Ministry of Health and Family Welfare (MOHFW). 1998. District Household Survey (Phase I). http://mohfw.nic.in/breakfile2.html. Accessed on May 10, 2004.

Ministry of Health and Family Welfare (MOHFW). 1999. District Household Survey (Phase II). http://mohfw.nic.in/break2file2.html.Accessed on May 10, 2004.

Ramachandar L and Pelto B. 2002. The role of village health nurses (VHNs) in mediating the abortions in rural Tamil Nadu, India. Reproductive Health Matters 10: 64-75.

Sood M, Juneja Y and Goyal U. 1995. Maternal mortality and morbidity associated with clandestine abortions. Journal of the Indian Medical Association 93(2): 77-79. 


\section{Authors}

Batya Elul is a programme associate, International Programs Division, Population Council, New York, NY, USA. Sandhya Barge is associate director, Centre for Operations Research and Training, Vadodara, India.

Shalini Verma was a research officer, Population Council, New Delhi, India, and is now a senior research manager at TNS India, New Delhi, India.

Nayan Kumar is a field manager, Centre for Operations Research and Training, Vadodara, India.

Hillary Bracken is a staff programme associate, International Programs Division, Population Council, New York, NY, USA.

Hemlata Sadhvani is a manager, research project, Centre for Operations Research and Training, Vadodara, India. 